\title{
Mitochondria as a target for neuroprotection: role of methylene blue and photobiomodulation
}

\author{
Luodan Yang ${ }^{1}$, Hannah Youngblood ${ }^{2}$, Chongyun $\mathrm{Wu}^{1}$ and Quanguang Zhang ${ }^{1 *}$ (D)
}

\begin{abstract}
Mitochondrial dysfunction plays a central role in the formation of neuroinflammation and oxidative stress, which are important factors contributing to the development of brain disease. Ample evidence suggests mitochondria are a promising target for neuroprotection. Recently, methods targeting mitochondria have been considered as potential approaches for treatment of brain disease through the inhibition of inflammation and oxidative injury. This review will discuss two widely studied approaches for the improvement of brain mitochondrial respiration, methylene blue (MB) and photobiomodulation (PBM). MB is a widely studied drug with potential beneficial effects in animal models of brain disease, as well as limited human studies. Similarly, PBM is a non-invasive treatment that promotes energy production and reduces both oxidative stress and inflammation, and has garnered increasing attention in recent years. MB and PBM have similar beneficial effects on mitochondrial function, oxidative damage, inflammation, and subsequent behavioral symptoms. However, the mechanisms underlying the energy enhancing, antioxidant, and anti-inflammatory effects of MB and PBM differ. This review will focus on mitochondrial dysfunction in several different brain diseases and the pathological improvements following MB and PBM treatment.
\end{abstract}

Keywords: Mitochondrial dysfunction, Neuroprotection, Methylene blue, Photobiomodulation

\section{Background}

There are several common causal factors for brain disorders, including oxidative stress, inflammation, transcriptional alterations, and excitotoxicity. Mitochondrial dysfunction plays a central role in the induction of these factors which lead to neurological disorders [1]. As a result, mitochondrial dysfunction has been the subject of several recent investigations studying the pathophysiology of neurological disorders [2-5]. In neurological disorders such as Alzheimer's disease (AD), traumatic brain injury (TBI), depression, stroke, and Parkinson's disease (PD), mitochondria contribute to the pathophysiology through decreased energy production and

\footnotetext{
* Correspondence: qzhang@augusta.edu

'Department of Neuroscience and Regenerative Medicine, Medical College of Georgia, Augusta University, 1120 15th Street, Augusta, GA 30912, USA Full list of author information is available at the end of the article
}

excessive production of reactive oxygen species (ROS) $[6,7]$. Research on mitochondrial dysfunction in brain diseases indicate that restoration of mitochondrial function is a potential method for treatment of neurodegeneration and other brain disorders [8-12]. Numerous studies indicate an improvement of brain mitochondrial function following treatment for neurological illness [13-15]. PBM and MB, the most widely studied approaches targeting mitochondrial respiration, were recognized as promising prospective treatments for brain disorders [16-20]. However, the mechanisms underlying the energy enhancing, antioxidant, and antiinflammatory effects of $\mathrm{MB}$ and $\mathrm{PBM}$ differ. Because $\mathrm{PBM}$ and $\mathrm{MB}$ exert beneficial effects through distinct mechanisms, combining the use of these two therapies is expected to improve therapeutic outcomes in a synergistic manner. 


\section{Main text}

\section{Mitochondrial structure and function}

Mitochondria are organelles found in eukayotic cells and are characterized by a double membrane structure [21]. In eukaryotic cells, the mitochondria generate the majority of adenosine triphosphate (ATP), which provides energy for cellular activities. The mitochondrial electron transport chain (ETC) is centrally involved in this ATP production. Five multi-subunit complexes in the mitochondrial inner membrane form the respiratory chain for oxidative phosphorylation [22]. As shown in Fig. 1, Complex I (NADH-ubiquinone oxidoreductase) and Complex II (succinate-ubiquinone oxidoreductase) work as the major entrance points for electrons into the respiratory chain. NADH and FADH2 transfer their electrons to Complex I and Complex II, respectively. These electrons flow between the complexes down an electrochemical gradient, shuttled by Complexes III and IV and by two mobile electron carriers, ubiquinone (Co-enzyme $\mathrm{Q} 10, \mathrm{CoQ})$ and cytochrome c (Cyt c) [23]. In the process of transfer, a proton motive force is established by pumping the protons through the inner mitochondrial membrane to the intermembrane space. Complex V (ATP synthase) depends on this process to generate ATP by phosphorylating ADP $[24,25]$.

A large body of evidence demonstrates that several changes induced by mitochondria, including oxidative stress, $\mathrm{Ca}^{2+}$ imbalance, dysfunctional electron transport, impaired mitochondrial trafficking, altered mitochondrial dynamics, and defective mitophagy, are involved in various brain diseases (Table 1) [32, 62, 79, 105-108]. Among these mitochondrial changes, oxidative stress and inflammation are the most directly related factors affecting the survival of neurons [109].

\section{Mitochondrial dysfunction}

Mitochondria are the primary source of ROS, as they use oxygen for energy production. As mentioned previously, the mitochondrial ETC is composed of five protein complexes, which are located in the inner mitochondrial membrane. The coenzymes NADH and FADH2 are responsible for electron transport along the ETC. This process is coupled with the transport of protons across the mitochondrial inner membrane, thereby forming an electrochemical proton gradient, which is used to drive ATP synthesis at Complex V. Although the process is relatively efficient, about 0.4 to $4 \%$ oxygen is incompletely reduced and produces ROS [10]. Under normal metabolic conditions, the main site of ROS generation is Complex III [110].

Certain levels of ROS are necessary for normal cellular function and healthy physiological processes, including response to anoxia, cellular signaling pathways, and the induction of a mitogenic response $[111,112]$. As reported, ROS signaling can lead to a cascade of cell-tocell communication, which allows a signal to propagate

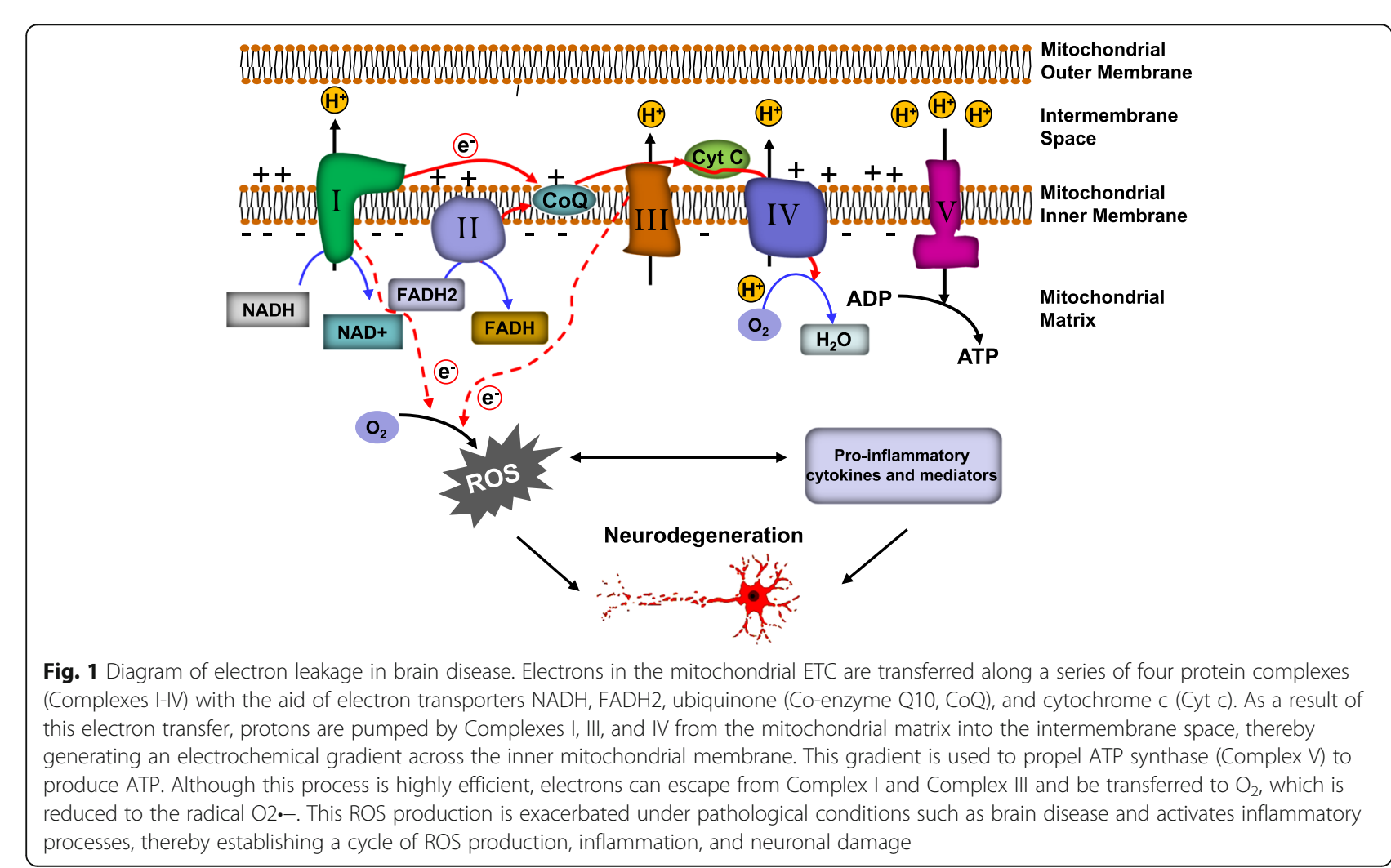


Table 1 Summary of mitochondria-related changes in brain disease

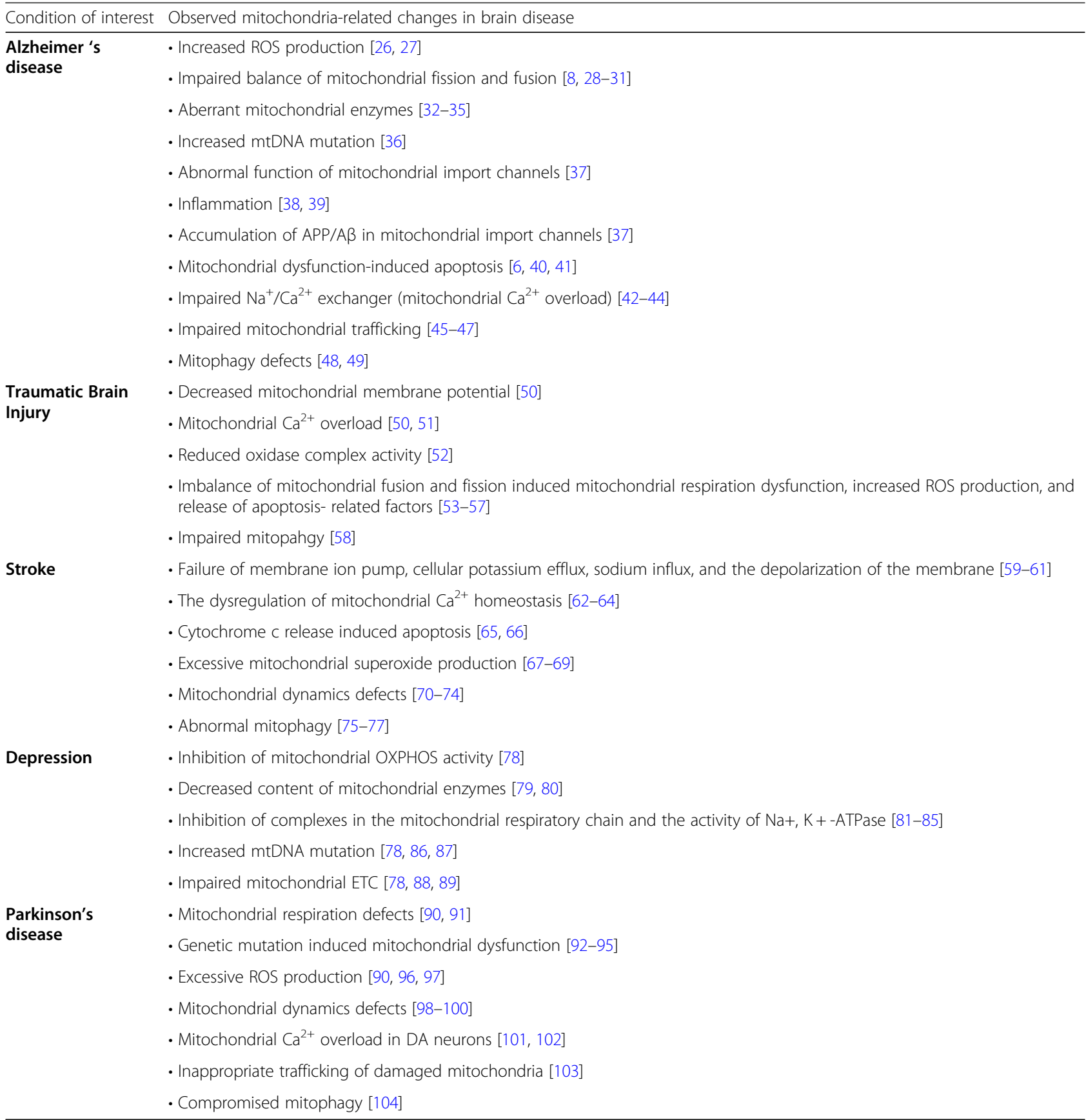

over long distances through different tissues [113]. Furthermore, the important role of physiological levels of ROS is exemplified in the immune system of granulomatous patients. Due to defects in the NADPH oxidase system, these patients cannot produce enough ROS to protect themselves from the persistent infections seen in many cases [112]. As mentioned above, ROS produced by mitochondria work as signaling molecules in response to stress, whereby transcriptional changes are initiated in the nucleus [114]. These transcriptional changes induce the increased expression of proteins contributing to improved systemic defense.

Although certain levels of ROS are beneficial, oxidative stress, characterized by excessive ROS production, has been recognized as a major contributing factor to the pathophysiology of several neurodegenerative diseases [10]. Mitohormesis describes the phenomenon in which low levels of ROS can be protective and beneficial while high levels of ROS can be deleterious [111, 112]. 
The production of ROS under various disease states overwhelms the maximum ability of defense mechanisms, wherein the excessive ROS production induces oxidative damage to lipids, proteins, and nucleic acids in the cell $[115,116]$. Because the integrity of the inner mitochondrial membrane is essential to the creation of an electrochemical gradient and ETC function, oxidative damage to the lipids and proteins that comprise the membrane results in further ETC dysfunction [117]. Furthermore, the impaired ETC enhances the overproduction of ROS, thus establishing an increasingly destructive cycle of oxidative stress and respiratory chain defects [118].

In addition to its effects on the ETC, high levels of ROS can also have deleterious effects on other aspects of mitochondrial function. $\mathrm{Ca}^{2+}$ plays a crucial role in the activation of mitochondrial enzymes, including pyruvate dehydrogenase, NAD-linked isocitrate dehydrogenase, and 2-oxoglutarte dehydrogenase [119]. Mitochondria can uptake $\mathrm{Ca}^{2+}$ into the mitochondrial matrix via the mitochondrial calcium uniporter complex (MCU) [120]. This process is driven by ATP hydrolysis and the electrochemical gradient produced by the ETC and regulates mitochondrial metabolism, cytoplasmic $\mathrm{Ca}^{2+}$ signaling, and cell death [121]. Under normal conditions, the uptake of calcium enhances mitochondrial respiratory function and tunes mitochondrial function to synaptic activity [122, 123]. However, excessive $\mathrm{ROS}$ generation can disturb $\mathrm{Ca}^{2+}$ homeostasis and induce $\mathrm{Ca}^{2+}$ overload. Elevation of $\mathrm{Ca}^{2+}$ levels can cause a change in mitochondrial potential and induce further production of ROS [124]. During this process, the mitochondria may undergo a collapse of membrane potential, increased mitochondrial permeability, and a rupture of the outer mitochondrial membrane [125]. The increased membrane permeability will finally result in cytochrome c release, thereby initiating cellular apoptosis [109, 121, 126].

Overproduction of ROS can also induce mitophagy by causing mitochondrial damage [127]. Mitophagy is the selective degeneration of mitochondria by autophagy in response to mitochondrial stress or damage [128]. During this process, the sustained depolarization of the inner membrane induces the accumulation of PTENinduced kinase 1 (PINK1) at the outer mitochondrial membrane [129]. The accumulation of PINK1 causes the phosphorylation of mitofusin 2 (Mfn2), the recruitment of Parkin to the outer mitochondrial membrane, the subsequent formation of phosphor-ubiquitin chains on mitochondrial outer membrane proteins, and the recruitment of autophagy receptors (e.g. OPTN, NDP52) [130]. These receptors bind to ubiquitin and LC3 forming an autophagosome [128]. Increasing evidence suggests that the inhibition of mitophagy results in mitochondrial dysfunction [128]. Impaired mitophagy has been demonstrated in most neurodegenerative diseases, including AD, PD, amyotrophic lateral sclerosis (ALS), and Huntington's disease [131, 132]. Impaired mitophagy cannot efficiently remove damaged mitochondria, which in turn enhances the overproduction of ROS and exacerbates the hyperinflammation induced by excessive ROS [132, 133].

In addition to mitophagy, the balance between mitochondrial fusion and fission (i.e. mitochondrial dynamics) has been recognized as a quality control mechanism. As a result, impaired mitochondrial dynamics has been considered as one of the intrinsic causes of mitochondrial dysfunction [134]. Evidence suggests that oxidative stress is able to cause excessive mitochondrial fission, which contributes to mitochondrial dysfunction [135, 136]. Furthermore, studies have found that knock-down of fission promoting protein Drp1 is able to attenuate the generation of pro-inflammatory factors and the production of ROS, indicating an important role for mitochondrial dynamics in protection against cellular damage [137].

In addition, a large body of evidence supports a cyclic relationship between mitochondrial dysfunction and inflammation [138]. It has been well established that mitochondrial perturbation and the release of mitochondrial components into the cytosol are able to induce innate immune response activation, which leads to increased release of inflammatory mediators [139-141]. Zhou et al., reported that ROS-generating mitochondria are able to induce inflammation through NLRP3 inflammasome-dependent inflammatory pathways [142]. Furthermore, the NLRP3 inflammasome complex can work as a mitochondrial dysfunction sensor [142]. This innate immune activation may occur due to a mitochondrial dysfunction prompted release of damage-associated molecular patterns (DAMPs) [143].

Mitochondrial DNA (mtDNA), a type of mitochondrial DAMP, can elicit a strong inflammatory response as it shares similarities to bacterial DNA [144]. As mentioned previously, under normal conditions, mitophagy is responsible for the degradation of defective mitochondria [128]. However, in brain disease, overproduction of ROS can result in impaired mitophagy which allows damaged mitochondria to go unchecked [145]. These defective mitochondria may eventually have a loss of membrane integrity allowing mtDNA to escape into the cytosol [146]. As a result, mtDNA may induce the release of type I interferon and the expression of other interferon-driven genes $[147,148]$.

Conversely, inflammation can also impact mitochondrial function. For example, IL-1 $\beta$ has been shown to 
induce mitochondrial fragmentation and decrease mitochondrial respiration rate via the mitochondrial fission-related protein Drp1 [149]. Furthermore, mitochondria treated with tumor necrosis factor alpha (TNF $\alpha$ ) have been shown to be smaller, more condensed, and hollow with fewer inner membrane folds (i.e. cristae). In addition, these mitochondria had a lower membrane potential, decreased intracellular ATP production, and significantly increased ROS generation [150]. Moreover, mitophagy increased in neuroblastoma cells following TNF treatment, suggesting an interplay between inflammation and mitophagy [151]. Taken together, this evidence provides strong support for a cyclic relationship between inflammation and mitochondrial dysfunction.

\section{Mitochondrial dysfunction in Alzheimer 's disease}

Alzheimer's Disease (AD) is a progressive, agedependent neurodegenerative disorder, characterized by progressive impairment of learning and memory, formation of neurofibrillary tangles (NFT), and extracellular deposition of amyloid- $\beta$ (A $\beta$ ) [152, 153]. In addition to these pathological hallmarks [153, 154], numerous studies have indicated that mitochondrial abnormalities are involved in the development of $\mathrm{AD}$. For example, hypometabolism, decreased cerebral blood flow, decreased oxygen extraction, and decreased oxygen utilization have been observed in $\mathrm{AD}$ patients [155-157]. In addition, increased oxidative stress and ROS production have also been observed in the brains of AD patients [158]. The observed increase in ROS generation is capable of inducing DNA, proteins, and lipid damage, a typical pathological signature in AD neural tissue $[26,27]$.

In addition to decreased regional blood flow and oxygen utilization, an impaired balance of mitochondrial fission and fusion has also been observed in the brains of $\mathrm{AD}$ patients $[28,29]$. The expression of mitochondrial fusion proteins, such as Opa1, Mfn1, and Mfn2, were downregulated, while the levels of the fission proteins Drp1, Fis1, Mff, and Mief were upregulated in AD, suggesting that an elevated ratio of fission over fusion proteins may have been contributing to mitochondrial and neuronal dysfunction $[8,28,30,31]$.

Furthermore, previous studies have found that aberrant mitochondrial enzymes, including Complex IV, pyruvate dehydrogenase complex, and the $\alpha$ ketoglutarate dehydrogenase complex, contribute to the development of AD [32-35]. One of the mechanisms underlying aberrant mitochondrial enzyme expression is the accumulation of mutations in the mtDNA sequences that code for subunits of these enzymes. Coskun et al., has shown that mtDNA mutations are more prevalent in $\mathrm{AD}$ patients than in healthy subjects [36]. In addition, reduced transcription of mtDNA L-strand ND6 and a decreased mtDNA/nuclear DNA ratio in AD patients has been suggested to decrease oxidative phosphorylation, and therefore, may account for some of the mitochondrial abnormalities observed in AD [36].

Moreover, mitochondrial calcium $\left(\mathrm{mCa}^{2+}\right)$ signaling is a key regulator in the aberrant mitochondrial enzyme-induced metabolic dysfunction associated with AD. In a mouse model of $\mathrm{AD}$, deletion of the $\mathrm{Na}^{+} /$ $\mathrm{Ca}^{2+}$ exchanger precedes memory deficits and significantly increased amyloidosis and tau hyperphosphorylation via metabolic dysfunction and excessive superoxide production, thereby suggesting that defective $\mathrm{mCa}^{2+}$ signaling contributes to $\mathrm{AD}$ progression [42, 43]. The $\mathrm{Na}^{+} / \mathrm{Ca}^{2+}$ exchanger is essential for proper nerve firing due to its removal of $\mathrm{Ca}^{2+}$ from nerve terminals [45].

Therefore, the number and functionality of mitochondria at axon terminals is critical. Impaired mitochondrial trafficking has been observed in $\mathrm{AD}$, and this transport defect is thought to contribute to the absence of mitochondria in presynaptic nerve terminals and may result in a diminished ATP supply in these areas [46]. The decreased local ATP supply may cause attenuated ATPdependent vesicular neurotransmitter loading and synaptic vesicle transport $[46,47]$.

Additionally, as mentioned previously, mitophagy is essential for maintaining normal neuronal function through the clearance of damaged mitochondria. $\mathrm{Nu}$ merous studies have demonstrated defective mitophagy in $\mathrm{AD}$ and have suggested approaches for restoring mitophagy as a strategy for ameliorating $\mathrm{AD}$ pathology [48, 49].

More directly, there have been studies supporting an interaction between dysfunctional mitochondria and abnormal processing of amyloid and tau. In the amyloid precursor protein (APP) transgenic mice model, APP is trapped in the mitochondrial membrane and affects mitochondrial function through the accumulation of APP/A $\beta$ in mitochondrial import channels [159]. The obstructed mitochondrial import channels impair the function of ETC enzymes and induce accumulation of toxic hydrogen peroxide species [37]. Furthermore, mitochondrial dysfunction has been shown to incite aberrant $A \beta$ production [160]. Chemical inhibition of mitochondrial ETC has been shown to enhance proteolytic APP processing, leading to increased levels of $A \beta$ [160]. Another study has found that an increased intracellular $\mathrm{A} \beta$ level in $\mathrm{AD}$-derived cybrids was accompanied by increased oxidative stress and neuronal apoptosis [161]. 


\section{Mitochondrial dysfunction in traumatic brain injury}

TBI is an injury often acquired through falls, sports accidents, motor vehicle crashes, violence, and other sources of physical trauma [162]. Following the physical injury, molecular changes in the cellular microenvironment, including mitochondrial damage, excessive ROS release, decreased ATP generation, neuronal loss, neuroinflammation, dysfunction of the blood-brain barrier (BBB), and edema formation, contribute to secondary injury [163, 164]. Among these, mitochondrial dysfunction plays a crucial role in TBI-induced neuronal apoptosis and necrotic cell death. For example, mitochondrial metabolism studies have provided evidence of reduced Complex IV activity persisting for up to 14 days after TBI [52]. In addition, after TBI, apoptotic proteins (Bak/ Bax) can induce mitochondrial swelling through membrane pore formation. During this process, small mitochondria-derived activator caspases are released, followed by apoptosome formation and neuronal apoptosis [163].

TBI causes both a continual release of excitatory neurotransmitters and an impairment, or even a reversal, of neurotransmitter uptake mechanisms, resulting in excessive levels of neurotransmitters in the synaptic cleft and subsequent excitotoxicity [165]. Voltage-dependent $\mathrm{Ca}^{2+}$ channels are one of the main mechanisms mediating excitotoxicity [165]. To buffer the influx of $\mathrm{Ca}^{2+}$ through these channels, mitochondria take up excess cytosolic $\mathrm{Ca}^{2+}$. This, however, is accomplished at the expense of mitochondrial membrane potential $(\Delta \Psi \mathrm{m})$ [165]. The resulting membrane depolarization can lead to ATP depletion, mitochondrial membrane permeabilization, and finally apoptosis or necrosis [165]. In addition, the mitochondrial $\mathrm{Ca}^{2+}$ overload could stimulate the over-production of ROS via activation of membrane permeability transition, cytochrome c release, pyridine nucleotide release, and respiratory inhibition [51, 166].

The balance of mitochondrial fission and fusion can also contribute to TBI-induced brain injury. The imbalance of mitochondrial fusion and fission, particularly excessive mitochondrial fission, has been shown to induce mitochondrial respiratory dysfunction, increased ROS production, and the release of apoptosis-related factors [53-57]. This imbalance of fusion and fission has been evidenced by a significant increase in the length of hippocampal mitochondria $24 \mathrm{~h}$ after TBI, followed by significantly decreased length $72 \mathrm{~h}$ post-injury [53]. Moreover, the level of mitochondrial fission-related protein Drp1 was significantly upregulated after TBI, indicating an increased mitochondrial fission that would account for the increased mitochondrial length observed [53]. Interestingly, inhibiting mitochondrial fission with the protein inhibitor Mdivi-1 prevented the later decrease in mitochondrial length and reduced the loss of newly formed neurons in the hippocampus [53].

Lastly, it has been reported that mitophagy in TBI is impaired. Damaged mitochondria are accumulated inside the neuronal cells and produce high levels of ROS that cause damage to other mitochondria and eventually induce neuronal death [53].

\section{Mitochondrial dysfunction in stroke}

Ischemic stroke is the most common type of stroke, occurring in more than $87 \%$ of cases [167]. It is usually caused by a blood clot-induced obstruction of one or more cerebral arteries in the brain [168, 169]. This obstruction prevents oxygen, glucose, and other nutrients required for cellular homeostasis to reach their destination within the ischemic brain. As a result, energy homeostasis and ATP synthesis are disturbed [168]. In fact, the insufficient supply of oxygen and glucose causes mitochondrial dysfunction within minutes after ischemia, leading to ATP depletion and ROS overproduction [168]. ATP depletion has been shown to induce a cascade of adverse cellular events, including failure of membrane ion pumps, cellular potassium efflux, sodium influx, and membrane depolarization [59-61]. One study has reported that the impairment of ATP-dependent $\mathrm{Ca}^{2+}$ channels can induce an overload of $\mathrm{Ca}^{2+}$ in the mitochondrial matrix, which further exacerbates ROS production and mitochondrial dysfunction [62, 65].

Excessive ROS production and increased membrane permeability induced by mitochondrial damage can lead to the initiation of the intrinsic apoptotic pathway $[66,170]$. This apoptotic process is dependent upon the release of cytochrome $\mathrm{c}$ from mitochondria into the cytosol [66]. Once released, cytochrome c, procaspase-9, apoptotic protease activating factor 1 (APAF-1), and dATP form a complex called an apoptosome in the cytosol [66]. The formation of the apoptosome induces the activation of caspase-9, which is followed by the activation of caspase- 3 and other executioner caspases that are responsible for accomplishing the apoptotic process [66].

In addition to ROS generation and apoptosis initiation, mitochondrial dynamics has also been implicated in ischemic stroke pathology [168]. The imbalance of mitochondrial fission and fusion has been well documented as an early event required for ischemia-induced neuronal death [70-72]. Mitochondrial fission has been found as early as $3 \mathrm{~h}$ after reperfusion in the middle cerebral artery occlusion (MCAO) mouse model for ischemic stroke [73]. As further support, the level of mitochondrial fission proteins Drp1 and Opa1 were found to be upregulated after MCAO [73]. Interestingly, it has been demonstrated that neurons resistant to ischemia can shift mitochondrial dynamics more towards fusion (i.e. 
less fission), suggesting that the balance of mitochondrial dynamics plays a critical role in neuronal response to ischemic injury [74].

On the other hand, the role of mitophagy in ischemic stroke remains controversial. Accumulating data has indicated that mitopahgy can be protective or destructive after stroke [75, 171-173]. Most studies support that mitophagy activation is a promising therapeutic target for ischemic stroke since mitophagy is able to remove impaired mitochondria and inhibit cell death signaling cascades [76, 77]. However, there are studies that have found that the inhibition of mitophagy confers a neuroprotective effect after MCAO and that excessive mitophagy can cause neuronal death after stroke [75].

Hemorrhagic stroke is the second most common type of stroke. Hemorrhagic stroke occurs when a weakened blood vessel bursts and bleeds into the surrounding brain. Reduced cerebral blood flow has been found in patients with intracerebral hemorrhage as well as experimental models [174-176]. This reduced blood flow has been closely associated with abnormal mitochondrial respiration and decreased basal mitochondrial ATP production [177]. It has also been reported that NMDA receptor is activated after intracerebral hemorrhage, thereby allowing a large $\mathrm{Ca}^{2+}$ influx and inducing an excessive production of superoxide through NADPH oxidase and the mitochondrial ETC $[63,64]$.

\section{Mitochondrial dysfunction in depression}

Increasing evidence implicates mitochondrial dysfunction in the pathogenesis of depression [21]. It is well-known that neurons mainly obtain energy from mitochondrial oxidative phosphorylation and that when oxidative phosphorylation is reduced, the production of ATP cannot meet the energy demand of the cell [178]. Chronic mild stress has been shown to inhibit oxidative phosphorylation, reduce mitochondrial membrane potential, and induce damage to the mitochondrial ultrastructure in the hippocampus, cortex, and hypothalamus of mouse models, thereby indicating a close relationship between mitochondrial dysfunction and depression [78, 179]. Another study found that the utilization of glucose in the prefrontal cortex, cingulate gyrus, and caudate nucleus was decreased in patients with depression, suggesting a decreased production of ATP $[80,180$, 181]. In line with this finding, other reports have demonstrated that production of mitochondrial ATP and expression of mitochondrial enzymes are decreased in patients with depression compared with healthy subjects $[79,80]$. These results were also demonstrated in muscle tissue from patients with depression [182]. Furthermore, several lines of evidence indicate depression pathology has a close relationship with the inhibition of complexes in the mitochondrial respiratory chain and the activity of $\mathrm{Na}+\mathrm{K}+-$ ATPase [81-85].

In addition, there are numerous studies suggesting an intriguing link between mtDNA and depression. In a previous study, $68 \%$ of depression patients have mtDNA mutations, compared to $35 \%$ of control subjects [80]. Similarly, mtDNA copy number variants were found to be significantly lower in leukocytes from depressive patients than in normal control subjects, while mtDNA oxidative damage was significantly higher [183]. Intriguingly, oxidized mtDNA was found to be able to activate pro-inflammatory cytokines and incite inflammation, which is known to play a critical role in depression [86, 184]. Furthermore, 16 mitochondrial genes (TIMM8B, SLC25A23, SFN, SLC25A30, UCP2, etc.) known to control the production of neuronal ATP and oxidative stress were found to be differentially expressed between depressive patients and healthy subjects [185].

A critical role of oxidative stress in depression has been demonstrated in several studies [186-188]. Since the mitochondrial ETC is the primary source of ROS-induced oxidative stress, ETC dysfunction has been hypothesized to be involved in the development of depression [78]. This oxidative stress is produced when complexes in the ETC incompletely reduce oxygen through the donation of electrons and subsequently generate oxygen radicals including peroxides and superoxide [88]. Excessive radicals are able to damage lipids and proteins, oxidize mtDNA, and incite DNA breaks [88, 89]. This process may play a key role in the pathogenesis of depression.

\section{Mitochondrial dysfunction in Parkinson's disease}

PD has been recognized as the second most common neurodegenerative disorder and is characterized by a progressive loss of dopaminergic (DA) neurons and the presence of Lewy bodies [189]. Increasing evidence supports mitochondrial dysfunction as one of the main contributors to PD pathogenesis [90]. A study on single neurons from idiopathic PD patients found that the abundances of Complex I and II were typically reduced [91]. Inhibition of Complex I has been shown to induce dopaminergic neurodegeneration in humans, flies, and rodents, indicating a critical role for mitochondrial dysfunction in PD $[90,190,191]$. In line with this, oxidative damage has been found in postmortem brain samples from PD patients [96].

Furthermore, certain mitochondria-related gene mutations capable of inducing mitochondrial dysfunction have been shown to cause familial forms of PD [92]. 
Mutations in numerous genes, including $S N C A, L R R K 2$, Parkin, PINK1, and ATP13A2, have been recognized as monogenic causes of familial PD [93]. These mutations have been directly associated with mitochondrial dysfunction [93]. Additionally, mtDNA in single neurons from idiopathic PD patients presented an increased number of multiple deletions on the background of a common deletion [93]. Consistently, an accumulation of mtDNA mutations and reduced mtDNA copy numbers were found in the substantia nigra from sporadic PD patients [94, 95]. However, the increased mtDNA copy number seen with age in controls was not found in PD patients [93].

In addition to genetic damage and mutations, the malfunction of mitochondrial fission and fusion can cause the death of dopaminergic neuronal cells in PD [98]. A previous study reported that PD-related genes (i.e. PINK1 and Parkin) play pivotal roles in regulating the balance of mitochondrial fission and fusion [99]. In a recent study using a neurotoxin model of sporadic PD, increased nitric oxide levels induced Parkin nitrosylation, resulting in the reduced ability of Parkin to suppress Drp1 and thereby causing mitochondrial hyperfragmentation [100].

Mitochondrial calcium overload was also found in PD. In dopaminergic neurons, excessive $\mathrm{Ca}^{2+}$ released from the endoplasmic reticulum impacted mitochondrial $\mathrm{Ca}^{2+}$ homeostasis, resulting in mitochondrial dysfunction and an apoptotic cascade [101]. Moreover, inhibition of mitochondrial $\mathrm{Ca}^{2+}$ overload was found to be able to render a neuroprotective effect in zebrafish models of PD [102].

Similar to other brain diseases, emerging evidence suggests that inappropriate trafficking of damaged mitochondria and compromised mitophagy contribute to mitochondrial dysfunction and PD pathogenesis [103, 104].

\section{Methylene blue and Photobiomodulation as therapeutic approaches}

A large body of evidence suggests a role for mitochondrial dysfunction in the pathogenesis of several brain diseases. As a result, much attention has been directed towards developing therapies for these diseases by targeting mitochondria and cellular respiration. Methylene blue and photobiomodulation are two such therapies.

Methylene blue (3,7-bis (dimethylamino)-phenothiazin-5-ium chloride, MB) is an FDA-approved medication which has been used as an effective agent in malaria treatment, methemoglobinemia, and cyanide poisoning [192, 193]. Recently, the potential role of $\mathrm{MB}$ in the treatment of neurodegenerative disorders, ischemic brain injury, and TBI has captured researchers' attention [9, 17, 22, 194-197]. Furthermore, its beneficial effects on psychosis has been reported in preclinical and clinical studies $[9,17,22$, 195-197]. In AD patients and AD animal models, cognitive performances were significantly improved after MB treatment [198, 199]. According to a randomized, double-blinded, placebo-controlled clinical trial, low-dose $M B$ was able to increase functional MRI activity during a short-term memory task and also improved memory retrieval [200]. In addition, MB has been tested in a human clinical trial in which patients with mild to moderate AD showed both cognitive and cerebral blood flow improvements after MB treatment [201]. The potential therapeutic role of MB for neurological disorders may result from a transformation between the reduced and the oxidized forms of MB [193]. During this process, MB can easily cross the blood-brain barrier and donate electrons from its reduced form to the mitochondrial electron transport chain (ETC), thereby increasing oxygen consumption and ATP formation [22, 202].

Intravenous administration of $\mathrm{MB}$ allows for higher available concentrations of the drug than oral administration, and therefore is the optimal means of delivery [201]. Following administration, MB can accumulate in various tissues at significant concentrations, with brain tissue concentration of $\mathrm{MB}$ being as much as 10 times higher than serum levels 1 hour post-injection [201]. The substantial accumulation in the brain allows MB to easily cross the $\mathrm{BBB}$ and preferentially enter neuronal mitochondria, although the mechanism for mitochondrial penetration is unclear [202]. Because MB readily crosses the $B B B$, has a strong affinity for mitochondria, and acts as a powerful antioxidant, the FDA approved MB to be routinely prescribed as an antidote for the treatment of poisoninduced methemoglobinemia [203-205].

Photobiomodulation (PBM), originally known as "low-level laser therapy (LLLT)", was first described almost 50 years ago and refers to the application of red-beam $(400-720 \mathrm{~nm})$ or near-infrared (700-1000 $\mathrm{nm}$ ) laser on biological tissues [206]. PBM therapy can modulate various biological processes and confer a protective effect against tissue damage and cell injury [8, 207, 208]. For example, studies found that LLI could promote the regeneration of gastrocnemius muscle after cold injury and enhance neovascularization after injury, indicating a potential role of PBM on regeneration and angiogenesis after muscle injury [209, 210]. In addition, the beneficial effects of PBM have been experimentally demonstrated on recurrent aphthous stomatitis, skin burn injuries, diabetes mellitus, sports injuries, and osteoarthritis [211-216]. Most significantly, PBM is able to confer its photobiological 
effect at the cellular level without thermal and toxic effects [217]. Interestingly, mitochondria are considered to be the target of PBM, wherein low-level laser donates photons to Complex IV, thereby increasing the activity of Complex IV and subsequent oxygen consumption [202, 218].

\section{Methylene blue, Photobiomodulation and AD}

In $\mathrm{AD}$, it has been found that mitochondrial malfunction often occurs before obvious plaque deposition and memory defects [219]. Previous studies have demonstrated an association between mitochondrial dysfunction and $A \beta$ accumulation $[31,220$, 221]. Accumulated $A \beta$ has been shown to be able to bind to the mitochondrial enzyme amyloid-binding alcohol dehydrogenase (ABAD), an enzyme responsible for the conversion of estradiol to estrone, a process which is important for mitochondrial protection [222-224]. This binding of $A \beta$ and ABAD has been shown to induce ABAD structural changes and result in the formation of an $A \beta-A B A D$ complex, leading to changes in mitochondrial membrane permeability and decreased respiratory enzyme activity [225]. However, interestingly, MB has been shown to decrease $A B A D$ overexpression, decrease $A \beta$ levels, and therefore decrease $A \beta-A B A D$ binding, thereby preserving $A B A D$ functions, attenuating mitochondrial dysfunction, and conferring a positive effect on $\mathrm{A} \beta$ accumulation [226].

An additional beneficial effect of $\mathrm{MB}$ on $\mathrm{AD}$ is the clearance of $\mathrm{A} \beta$ through increased activity of chymotrypsin and trypsin-like proteasome [199]. Previous studies treating 3xTg-AD and APP/PS1 mouse models with $\mathrm{MB}$ demonstrated a decreased deposition of $\mathrm{A} \beta$ and improvement of learning and memory through chymotrypsin and trypsin-like proteasome activation and $\beta$-secretase activity attenuation [198, 199, 227]. Similar results were found on the transgenic PSAPP mice wherein $\mathrm{MB}$ was reported to be able to attenuate the activity and expression of $\beta$-secretase [198]. In this way, MB has been shown to inhibit the formation of neurotoxic oligomeric $A \beta$ and improve behavioral results $[19,20]$.

NFT aggregated by hyperphosphorylated tau protein (p-tau) is another pathological hallmark of AD [228]. MB has been reported to inhibit this aggregation by attenuating tau-tau interactions [229]. Furthermore, $\mathrm{MB}$ is also able to prevent the formation of tau filament by acting on the microtubule binding domain [230]. In a previous in vitro study, the $\mathrm{N}$ unsubstituted phenothiazine ring of $\mathrm{MB}$ was found to be necessary for the inhibition of filament formation [230]. In a clinical study, patients with mild to moderate $\mathrm{AD}$ took $\mathrm{MB}$ orally at $60 \mathrm{mg}$ three times daily for 24 months [229]. Results showed that patients with MB showed an $81 \%$ reduction in the rate of cognitive decline after 50 weeks compared with controls [229]. The authors suggested that the beneficial effect of $\mathrm{MB}$ on $\mathrm{AD}$ patients was linked to the prevention of tau aggregation [229].

In addition, $M B$ has been suggested to directly interact with the mitochondrial ETC as a catalytic redox cycler carrying electrons from NADH to Complex IV [17, 22]. During the conversion between $\mathrm{MB}$ and its reduced counterpart Leuco MB, excessive ROS is reduced by bypassing the pathological blockage of Complex I and III $[17,22]$. MB is also known to be able to enhance the activity of Complex IV as well as upregulate heme synthesis, and thereby promote mitochondrial function in the AD brain [231-233].

The neuroprotective effect of PBM on AD has also been well established over the past few decades. In an amyloid- $\beta$ protein precursor $(\mathrm{A} \beta \mathrm{PP})$ transgenic mouse model, the amount of $A \beta$ plaques and amyloid was significantly reduced and was accompanied by improved behavioral results [234]. In another transgenic mouse model (K369I tau transgenic model), the levels of hyperphosphorylated tau and neurofibrillary tangles were significantly decreased as was the expression of oxidative stress markers [235]. Recently, a new perspective on the mechanism of $\mathrm{PBM}$ in $\mathrm{AD}$ treatment was proposed, in which mesenchymal stem cells stimulated by PBM were shown to maturate towards a monocyte lineage, thereby increasing the ability of $A \beta$ phagocytosis in vitro [236]. Furthermore, PBM has been shown to improve spatial learning and memory ability by significantly reducing $A \beta$ burden in the brain [236]. An in vitro study reported that PBM was able to exert neuroprotection against $A \beta$ toxicity and inhibit dendritic spine loss in neurons by activating the ERK/CREB pathway and upregulating the expression of BDNF [237].

Similarly to $\mathrm{MB}$, the effect of PBM on AD occurs mechanistically through the improvement of mitochondrial function $[40,238]$. In a previous study, we demonstrated the beneficial effects of PBM on the streptozotocin (STZ) induced AD model [8]. These beneficial effects occurred via several mitochondriarelated mechanisms. First, we showed that PBM can inhibit the expression of mitochondrial fission-related proteins and improve the expression of fusion-related proteins, which directly improves mitochondrial dynamics [8]. Secondly, the restoration of mitochondrial dynamics facilitated mitochondrial homeostasis by decreasing the $\mathrm{Bax} / \mathrm{Bcl}-2$ ratio elevated by STZ injection [8]. Furthermore, our study demonstrated that PBM was able to suppress the oxidative damage and inflammation seen in $\mathrm{AD}$ [8]. 


\section{Methylene blue, Photobiomodulation and TBI}

Since mitochondrial dysfunction is well studied in $\mathrm{TBI}$, the ability of $\mathrm{MB}$ to treat mitochondrial dysfunction as a means of neuroprotection has been the subject of investigation. In addition to the beneficial effects seen in other neurological diseases, $\mathrm{MB}$ has been found to be able to reduce TBI-induced edema, attenuate lesion volume, and improve behavioral scores [163]. In previous studies, MB has been reported to be able to cross the blood-brain barrier and accumulate in the brain with 10-20 times higher concentration than that in the circulation after intravenous injection [163]. No side effects have been reported in animals given a low dose of MB (0.5-5 mg/kg) [239, 240]. However, it must be noted that adverse effects can occur with high doses of $\mathrm{MB}$ (>10 mg/kg) due to the interference with the ETC [239].

In a study using a low dose of $\mathrm{MB}(1.5 \mathrm{mg} / \mathrm{kg})$ on the first day of TBI, edema was shown to significantly decrease in the injured hemisphere [241, 242]. This sort of edema reduction is critical in reducing TBIassociated mortality. The effect of $\mathrm{MB}$ on the number of surviving neurons has also been determined by a previous study. At 24 and $72 \mathrm{~h}$ post-TBI, the number of surviving neurons after $\mathrm{MB}$ treatment was significantly increased compared with the group treated with vehicle injection. In addition, increased Belin 1 expression and an increased LC3-II to IL3-I ratio were found in $\mathrm{MB}$ groups, indicating an increased induction of autophagy [241].

Recently, a study using in vitro cell (oxygen glucose deprivation/reoxygenation injury, OGD) and TBI animal models determined whether $\mathrm{MB}$ treatment was able to confer beneficial effect on neuronal mitochondrial dysfunction. In the OGD model, they demonstrated $\mathrm{MB}$ treatment was able to inhibit excessive neuronal ROS production, maintain mitochondrial membrane potential, and induce increased ATP generation, indicating that $\mathrm{MB}$ is able to attenuate OGD induced-mitochondrial dysfunction [243]. This was further confirmed by blood brain barrier protection and decreased cytochrome $\mathrm{c}$ release and neuronal apoptosis in the TBI animal model after MB treatment [243].

In addition to $\mathrm{MB}, \mathrm{PBM}$ has been suggested as a possible therapeutic strategy for TBI since PBM has been reported to increase mitochondrial function, improve blood flow, reduce swelling, decrease oxidative stress, inhibit inflammation, and attenuate apoptosis [244]. Exposing an injured mouse head (TBI) to PBM with a near-infrared laser $(808 \mathrm{~nm})$ has been shown to improve neurological performance and decrease lesion size [245]. Interestingly, laser wavelength seems to play a role in PBM efficacy since PBM with $665 \mathrm{~nm}$ and $810 \mathrm{~nm}$ wavelength lasers caused significant neurological improvement while PBM with $730 \mathrm{~nm}$ and $980 \mathrm{~nm}$ wavelength lasers did not [246]. This phenomenon may be explained by the target of the laser light. Complex IV is proposed to absorb laser light between $665 \mathrm{~nm}$ and $810 \mathrm{~nm}$, suggesting that it is the target of PBM treatment [246]. An elevation of ATP production following PBM treatment in mice with mild head TBI supports the proposed role of the mitochondrial ETC as the cellular target for PBM [247].

The efficacy of PBM on TBI has also been shown in TBI patients. Learning memory, mathematical skills, and neuropsychological test results were significantly improved after 9 months of PBM treatment [248]. Moreover, a patient who had suffered severe TBI could spontaneously move his arm and hand after 5 days of PBM treatment [249].

\section{Methylene blue, Photobiomodulation and stroke}

Another neurological disorder for which $\mathrm{MB}$ and PBM has been proposed is stroke $[16,250]$. In a focal cerebral ischemia rat model, behavioral results were significantly improved after chronic oral $\mathrm{MB}$ treatment [16]. Further studies demonstrated its beneficial role in decreasing total lesion volume, cerebral edema, and gray and white-matter damage, all of which contributed to the improvement of behavioral results $[16,18]$. Lin et al., demonstrated that MB treatment was able to improve the activity of mitochondrial Complexes I, II, and III and significantly increase both oxygen consumption and glucose uptake in HT22 cells, a well-known neuronal cell line [251]. Their in vivo experimental results indicated that cerebral global glucose uptake and blood flow were significantly increased in animals treated with MB [251]. Furthermore, an in vitro study found that oxygen consumption rate increased after $\mathrm{MB}$ treatment even under the inhibitory effect of Complex I, III, and V inhibitors [252]. In addition, neuronal ATP production has been shown to improve with $\mathrm{MB}$ treatment [252]. In a MCAO rat model, the decreased activity of Complex I, III, and IV after ischemia/reperfusion injury contributed to decreased mitochondrial function, which was restored with a low-dose of MB [252].

One of our previous studies found that MB was able to attenuate stroke-induced behavioral defects and improve neurogenesis in the peri-infarct area by increasing mitochondrial function [9]. The underlying mechanism for this recovery was the improvement of the mitochondria-dependent microenvironment around newborn neurons [9]. 
Furthermore, in an acute cerebral ischemic injury model, improvement of neurological function was determined to be related to the augmentation of mitophagy wherein $\mathrm{MB}$ was able to attenuate the ischemia-induced disintegration of the mitochondrial structure [253]. However, the effects of mitophagy in stroke remains controversial. The neuroprotective role of $\mathrm{MB}$ in cerebral ischemia has also been suggested to be caused by increased mitophagy and the maintenance of mitochondrial membrane potential [253].

Similarly to MB, PBM therapy has been proposed as a promising therapeutic approach for stroke [254]. Previous studies on animals have demonstrated that PBM treatment using 660-808 nm low-level laser improved neurological rating scores without thermal effects $[4,255,256]$. Similarly, the safety and efficacy of using infrared laser therapy within $24 \mathrm{~h}$ of stroke onset has been validated in a human patient study [257]. In line with these studies, a large body of research on LED-PBM using in vitro cell assays has been published $[258,259]$. In both human epithelial cells (HEP-2) and mouse subcutaneous connective tissue cells (L-929), PBM treatment increased metabolism and proliferation [258]. The association between ischemic stroke and dementia has been well studied in previous studies [260, 261]. Interestingly, PBM also displays protective effects in dementia patients after ischemic stroke by stimulating cerebral neurogenesis [262]. In a study using a photothrombotic (PT) model of ischemic stroke, PBM was observed to improve behavioral results by enhancing mitochondrial function and neurogenesis [4].

Similarly to $\mathrm{MB}$, neuronal mitochondria are regarded as the target for PBM. PBM initiated $6 \mathrm{~h}$ after GCI was shown to protect against CA1 neuronal cell death through the preservation of healthy mitochondrial dynamics and the suppression of mitochondrial fragmentation [263]. During this process, the preservation of mitochondrial integrity by PBM attenuated mitochondrial oxidative damage and excess mitophagy and suppressed mitochondriadependent apoptosis [263]. In a study using a neonatal animal model, hypoxia ischemia (HI)-induced brain lesions in the cortex and hippocampus were significantly decreased after PBM treatment [254]. Further mechanistic investigations indicated that PBM could attenuate HI-induced mitochondrial fragmentation and significantly restore mitochondrial dynamics [254]. In addition, PBM inhibited HI-induced mitochondrial membrane collapse, improved ATP production, and decreased protein carbonylation, DNA oxidative damage, and lipid peroxidation [254].

\section{Methylene blue, Photobiomodulation and depression}

In an early study in 1983, MB was recognized as a potential method for manic depression [197]. In their study, oral MB administration significantly improved the symptoms of 14 of 19 manic depressive patients for whom standard therapies failed [197]. In line with this, MB was also shown to be an effective addition in the long-term treatment of depression in a double-blind clinical trial [264]. Moreover, MB can work effectively even on severe depression. The symptoms of patients included in a controlled trial with severe depressive illness were significantly improved after receiving $15 \mathrm{mg} /$ day MB treatment [265]. Previous studies have also confirmed the efficacy of MB for the treatment of bipolar disorder [266]. Furthermore, depressive-like behavior in both human patients and animal models can been observed after TBI [267, 268]. However, MB has been shown to inhibit this depressive-like behavior [269].

These improvements may be explained mechanistically by the role of nitric oxide (NO), an unconventional gaseous neurotransmitter, in mood disorders and by the selective inhibition of nitric oxide synthase (NOS) [264, 265, 270, 271]. Not only does MB inhibit NOS in the brain, but it also affects other heme-containing enzymes including various cytochromes [272, 273].

PBM has also been suggested to have a potential antidepressant role. In a study of reserpine-induced depression, the results of the forced swimming test, which tests mobility, improved after PBM treatment [274]. In addition, after several weeks of laser acupuncture intervention, symptoms improved significantly in depressive patients $[275,276]$. Furthermore, depressive symptoms evidenced improvement after transcranial ( $\mathrm{t}-\mathrm{PBM})$ and intranasal (i-PBM) treatment in a case report on a 76-year-old female with major depressive disorder [277]. The beneficial effects of $\mathrm{PBM}$ on depression have also been demonstrated in a space restriction-induced depression animal model and in Abelson helper integrationsite-1 (Ahi1) KO mice [208]. In both of these two mouse models of depression, depressive behaviors were effectively improved by PBM [208]. Further mechanistic investigation suggested that ATP production and the activity and expression of mitochondrial Complex IV were significantly improved after PBM treatment [208]. Therefore, PBM may attenuate behavioral deficits in depression by improving energy metabolism.

\section{Methylene blue, Photobiomodulation and Parkinson's disease}

As mentioned earlier, PD, the most common movement disorder, is characterized by mitochondrial dysfunction 
although the underlying mechanism contributing to the dopaminergic neuronal damage remains unclear [90]. However, mitochondrial dysfunction-induced oxidative stress has been closely linked to the loss of neurons in PD $[278,279]$. In a 6-OHDA-induced PD model, 6OHDA administration was performed to induce dopamine depletion and cause disruption of mitochondrial function and excessive production of ROS [280-283]. Because of the antioxidant properties of $\mathrm{MB}$, a research group anticipated that $\mathrm{MB}$ administration could confer neuroprotective effects on substantia nigra pars compacta (SNc) dopamine cells [284]. Although it was not accompanied by improved behavioral results, a low dose of orally administered MB mitigated 6-OHDA-induced SNc dopamine cell loss [284].

In rotenone model of $\mathrm{PD}$, similar results were found when $\mathrm{MB}$ was able to attenuate rotenoneinduced inhibition of mitochondrial Complexes I, II, and III, reduce free radical production, and improve behavioral results [252, 285]. A study using an MPTP (1-methyl-4-phenyl-1, 2, 3, 6tetrahydropyridine)-induced PD animal model to evaluate the effect of $\mathrm{MB}$ on dopamine cells found that $\mathrm{MB}$ could cause the upregulation of brainderived neurotrophic factor (BDNF) and induce the activation of its downstream signaling pathways, indicating BDNF may be one of the contributing factors for MB-mediated neuroprotection [286].

6-OHDA and MPTP-induced PD animal models have also been widely used in the study of PBM treatment of PD. In these models, PBM treatment was able to fully rescue lesions with $15 \%$ cell loss $[287,288]$. However, lesions with up to $50 \%$ cell loss were unrecoverable [289]. These results were confirmed in a lipopolysaccharide
(LPS)-induced dopaminergic cell loss rat model [290]. PBM could fully rescue rats from 15\% LPS-induced cell loss by inhibiting inflammatory amoeboid microglia, however, there was no significant neuroprotection on groups with 50\% cell loss [290].

PBM has also been used in a randomized clinical trial in which the heads of PD patients were exposed to red light-emitting diodes (LED) for a 9-week time course [291]. After 9-weeks treatment, there was no significant difference in the sham group [291]. However, PBM groups presented significant gait improvement [291]. Another clinical report showed an improvement in speech, cognition, gait, and freezing episodes in PD patients administered 2 weeks of PBM therapy [292]. Given evidence from studies on PBM treatment for other neurodegenerative disease, it is plausible that the mechanism underlying the beneficial effect of PBM on PD could be due to improved mitochondrial function and reduced oxidative stress [293].

\section{Primary mechanisms underlying mitochondrial protection through MB and PBM}

As reported, both $\mathrm{MB}$ and $\mathrm{PBM}$ are known to enhance energy production and decrease oxidative stress [294-296]. However, the underlying mechanism for these effects differs between the two treatments. As shown in Fig. 2, MB works as a catalytic redox cycler which is reduced in the mitochondrial matrix by electrons donated from NADH $[297,298]$. This results in the formation of $\mathrm{MBH}_{2}$, also called Leuco $\mathrm{MB}$. $\mathrm{BH}_{2}$ is able to bypass the compromised ETC between Complex I and Complex III and readily recycle between

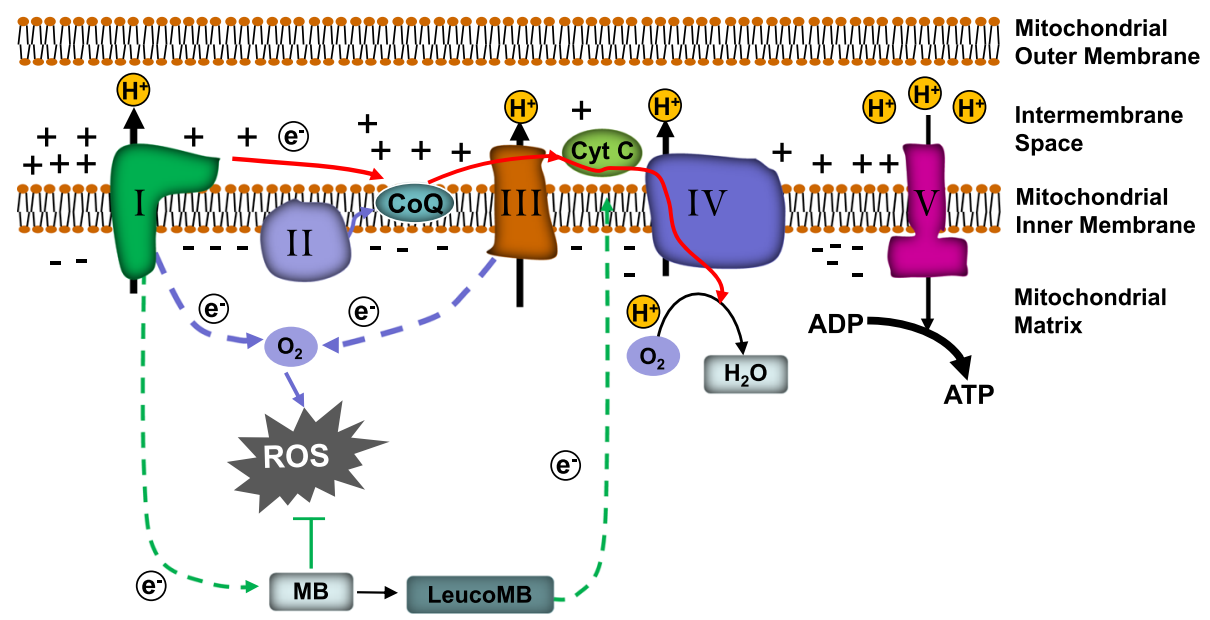

Fig. 2 Primary Mechanisms Underlying Mitochondria Protection through MB. MB reroutes the pathway of electron transfer by working as an alternative electron transporter. By bypassing the ETC between Complex I and Complex III, MB efficiently attenuates electron leakage and subsequent ROS generation 
its reduced form and oxidized form due to its low redox potential [297, 298].

As mentioned previously, mitochondria are the major site for ROS generation. Under pathological conditions, Complex I and Complex III act as the main sites for electron leakage in mitochondria [22]. The electrons leaking from Complex I and Complex III are transferred to $\mathrm{O}_{2}$, reducing it to O2 - [299]. The excessive ROS will primarily damage Complex I and Complex IV, which will induce additional mitochondrial dysfunction [299, 300]. Moreover, high levels of ROS and oxidized mitochondrial DNA can induce the activation of the NLRP3 inflammasome, which triggers an innate immune response through the release of pro-inflammatory cytokines [142, 301-303]. However, the oxidation/reduction of MB can act as an alternative mitochondrial electron transfer pathway. By bypassing Complex I and Complex III, MB efficiently attenuates electron leakage and subsequent ROS generation [22]. Due to the reduction of ROS, MB can also play a role in the inhibition of inflammation. Although several mechanisms underlying the neuroprotective effects of MB have been reported, including caspase- 6 activity inhibition [304], restoration of PMCA pump function [305], PI3K/Akt/GSK3 $\beta$ pathway activation [306], reduction of pro-inflammatory cytokines [286], attenuation of synaptic toxicity and MARK4/
PAR1-mediated tau phosphorylation [286], Nrf2/ ARE signaling pathway activation and MEF2Dassociated survival pathway induction [307], the possibility that mitochondria are involved in those processes cannot be excluded [304].

The mechanism for the beneficial effects of PBM on mitochondrial function, however, is quite different and depends on chromophores located within the cells. According to the first law of photobiology, PBM must be absorbed by a chromophore within the tissue of interest in order to confer biological effects; mitochondria play a key role in this light absorption [308].

Complex IV (cytochrome c oxidase, CCO) in the ETC contains 13 separate protein subunits with two heme moieties (heme $\alpha$ and hem $\alpha_{3}$ ) and two redox-active copper centers $\left(\mathrm{Cu}_{\mathrm{A}}\right.$ and $\left.\mathrm{Cu}_{\mathrm{B}}\right)$ along with one zinc and one magnesium center, which are all believed to be absorbing chromophores for visible light $[295,309]$. In the process of ATP generation, Complex IV transfers four protons along with the electrons from reduced cytochrome $\mathrm{c}$ to oxygen to form two $\mathrm{H}_{2} \mathrm{O}$ molecules [22, 295]. This process contributes to the formation of the proton gradient which drives the activity of ATP synthase [22, 295].

According to previous studies, PBM is considered to enhance the activity of Complex IV and subsequently improve the generation of ATP (Fig. 3) [295]. This enhanced activity has been suggested to be due

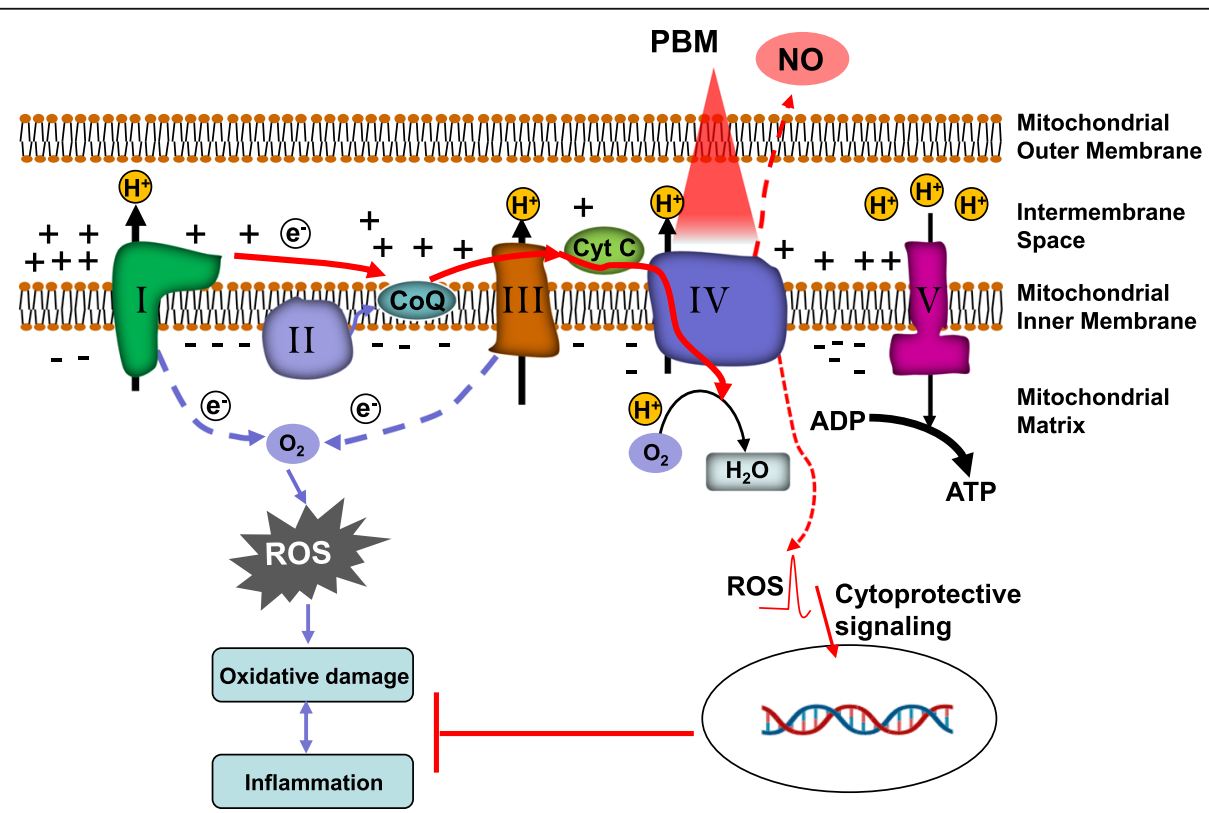

Fig. 3 Primary Mechanisms Underlying Mitochondria Protection through PBM. PBM treatment causes NO to dissociate from Complex IV (cytochrome c oxidase, CCO), causing the complex's activity to increase. This allows the flux of electrons, the pumping of protons, and the synthesis of ATP to increase, thereby boosting cellular energy levels. In addition, when PBM stimulates Complex IV activity in normal cells, mitochondrial membrane potential is increased above normal baseline levels, resulting in a brief and rather modest increase in ROS production. The short burst of ROS is able to activate cytoprotective signaling, which attenuate ROS induced oxidative damage and neuroinflammation 
to a PBM-mediated photodissociation of $\mathrm{NO}$ from Complex IV [310]. NO is a molecule inhibiting Complex IV by non-covalently binding to heme $\alpha 3$ and $\mathrm{CuB}[310,311]$. When $\mathrm{NO}$ is photodissociated from Complex IV, the activity of Complex IV is enhanced, improving energy production [310]. Under normal conditions, ROS is generated at low levels by normal mitochondrial metabolism [310]. When PBM stimulates Complex IV activity in normal cells, mitochondrial membrane potential is increased above normal baseline levels, resulting in a brief and rather modest increase in ROS production [312]. The short burst of ROS is able to activate NF-kB in the cytoplasm [312]. The released NF-kB will be transported from the cytoplasm to the nucleus, where it will induce the expression of more than 150 genes, including genes related to mitochondrial dynamics, inflammation, and antioxidant activity [217].
In pathological states, the increased mitochondrial membrane potential mediated by PBM is able to lower ROS production $[217,295]$. As result, pro-inflammatory NF-kB activity is lowered. Evidence has demonstrated that PBM is able to attenuate the levels of proinflammatory cytokines produced from activated inflammatory cells [313-315]. This anti-inflammatory effect of $\mathrm{PBM}$ may due to its ability to mediate the transformation between the M1 "pro-inflammatory" phenotype and the M2 "anti-inflammatory" phenotype of microglia although the exact mechanism is unclear $[4,206]$.

\section{Conclusion}

$\mathrm{MB}$ and $\mathrm{PBM}$ are two promising therapeutic approaches for brain disorders. Both MB and PBM target mitochondria, although their underlying mechanisms differ (Table 2). The studies discussed offer compelling evidence that suggests mitochondrial dysfunction could be a potential target

Table 2 Summary of effects of MB or PBM on neurodegenerative disorders and brain injury

\begin{tabular}{|c|c|c|}
\hline Disease & Effect of a treatment with $M B$ & Effect of a treatment with PBM \\
\hline \multirow[t]{4}{*}{$A D$} & - Increases functional MRI activity and improves memory retrieval [200] & $\begin{array}{l}\text { - Reduces hyperphosphorylated tau, neurofibrillary } \\
\text { tangles, and oxidative stress }[234,235]\end{array}$ \\
\hline & - Decreases A levels and A $\beta-A B A D$ binding [226] & - Increases the ability of A $\beta$ phagocytosis [236] \\
\hline & $\begin{array}{l}\text { - Attenuates the activity and expression of } \beta \text {-secretase, inhibits the formation of } \\
\text { neurotoxic oligomeric } A \beta \text {, and improves behavioral results }[19,20,198]\end{array}$ & $\begin{array}{l}\text { - Improves spatial learning and memory by } \\
\text { significantly reducing } A \beta \text { burden [236] }\end{array}$ \\
\hline & & - Exerts neuroprotection by activating the \\
\hline
\end{tabular}

- Inhibits p-tau aggregation and tau-tau interactions [229, 230]

- Reduces excessive ROS production $[17,22]$

- Upregulates Complex IV activates, heme synthesis and mitochondrial function [226, 231-233]

TBI

- Decreases edema and lesion volume and improves behavioral scores [163]

- Increases autophagy [242].

- Inhibits excessive ROS production and attenuates mitochondrial dysfunction, cytochrome c release, and neuronal apoptosis [243]

Stroke

- Improves behavioral results after focal cerebral ischemia [16]

- Decreases lesion volume, cerebral edema, and gray and white- matter damage $[16,18]$

- Increases cerebral global glucose uptake and blood flow [251, 252]

- Increases mitochondrial function [9, 252]

- Preserves mitochondrial structure and function [253]

- Increases mitophagy and preserves mitochondrial membrane potential [253]

Depression - Improves the symptoms of patients with severe depression [265]

- Selectively inhibits nitric oxide synthase (NOS) [264, 265, 270, 271]

PD

- Attenuates dopamine loss and reduces the disruption of mitochondrial function and excessive production of ROS [280-284]

- Improves Complexes I, II, and III activities, reduces free radical production, and improves behavioral results [252, 285]

- Upregulates brain-derived neurotrophic factor (BDNF) expression [286]
ERK/CREB pathway and upregulating the expression of BDNF [237]

- Restores mitochondrial dynamics [8]

- Neurological improvement [246]

- Increases mitochondrial function, improves blood flow, and reduces swelling [244, 247]

- Decreases oxidative stress, inhibits inflammation, and attenuates apoptosis [244, 247]

- Improves neurological rating scores $[4,255,256]$

- Stimulates neurogenesis and improves mitochondrial function $[4,262]$

- Preserves mitochondrial integrity [263]

- Attenuates mitochondrial fragmentation and restores mitochondrial dynamics [254]

- Decreases protein carbonylation, DNA oxidative damage, and lipid peroxidation [254]

- Improves depressive symptoms [274-277]

- Improves ATP production and increases activity and expression of mitochondrial Complex IV [208]

- Reduces cell loss and inhibits inflammatory amoeboid microglia [287-290]

- Improves speech, cognition, gait, and freezing episodes in PD patients [291, 292]

- Improves mitochondrial function and reduces oxidative stress [293] 


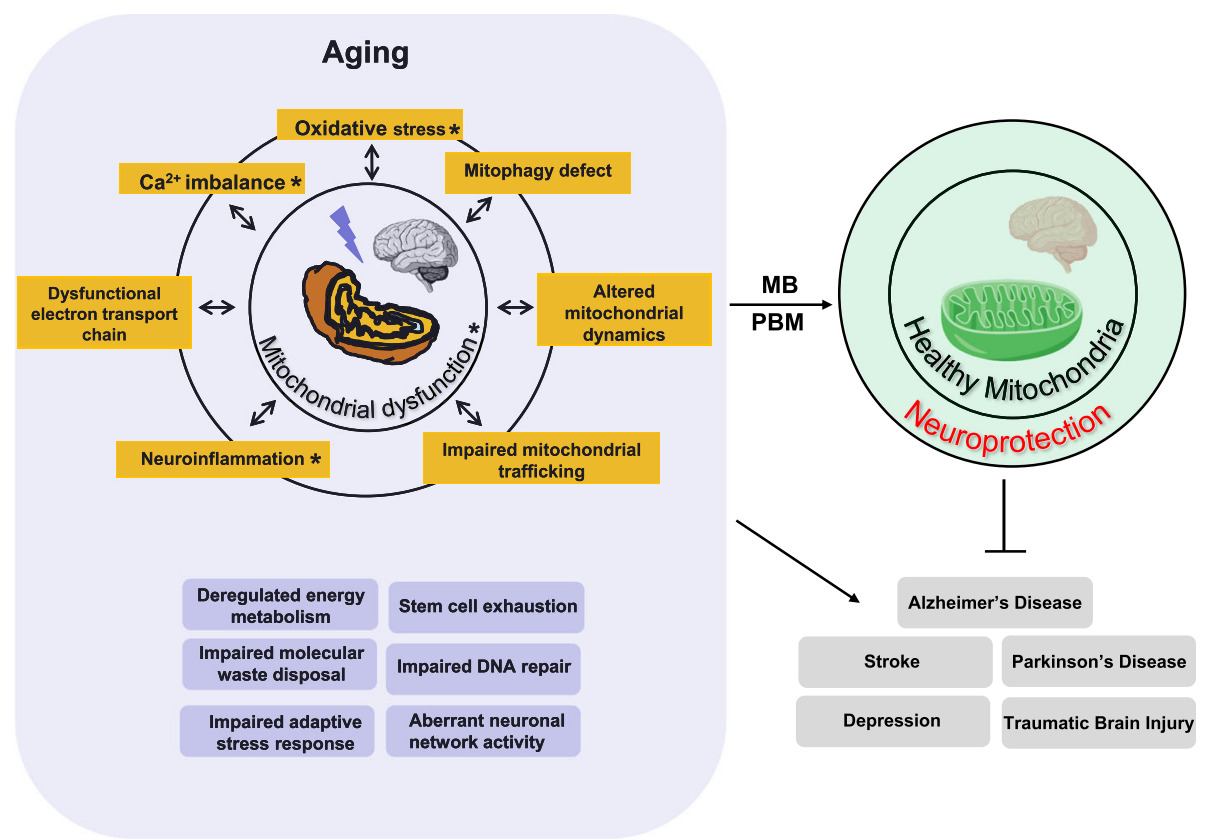

Fig. 4 Mitochondrial related changes associated with mitochondrial dysfunction. Mitochondrial dysfunction, oxidative damage, dysregulated neuronal $\mathrm{Ca}^{2+}$, and neuroinflammation are hallmarks of brain aging (the other six hallmarks are deregulated energy metabolism, stem cell exhaustion, impaired molecular waste disposal, impaired DNA repair, impaired adaptive stress response, and aberrant neuronal network activity) . Increasing evidence suggested the hallmarks of brain aging affect several brain disease etiologies [316, 317]. MB and PBM can attenuate the pathological symptoms of several brain diseases and lead to neuroprotection by reducing various aspects of mitochondrial dysfunction

for neuroprotection for several brain disorders. The mitochondrial dysfunction-related processes that could be targeted and improved upon include impaired ETC function, excessive ROS production, oxidative damage, $\mathrm{Ca}^{2+}$ overload, aberrant mitophagy, altered mitochondrial dynamics, impaired mitochondrial trafficking, and subsequent neuroinflammation (Fig. 4), of which most are included in the 10 hallmarks of brain aging reported recently [316, 317]. Since $\mathrm{MB}$ and PBM both target mitochondria through distinct mechanisms, a therapy combining their use may be able to ameliorate the symptoms of brain disease beyond the ability of either individual therapy. Such a combined therapy warrants serious future investigation in animal studies and clinical trials. If proven effective, the combined use of $\mathrm{MB}$ and PBM may provide a promising new avenue for the treatment of multiple brain diseases.

\footnotetext{
Abbreviations

ABAD: Amyloid-binding alcohol dehydrogenase; AD: Alzheimer's disease; Ahi1: Abelson helper integrationsite-1; ALS: Amyotrophic lateral sclerosis; APE-1: Apoptotic protease activating factor 1; APP: Amyloid precursor protein; ATP: Adenosine triphosphate; AB: Amyloid- $\beta$; AßPP: Amyloid- $\beta$ protein precursor; BBB: Blood-brain barrier; BDNF: Brain-derived neurotrophic factor; CAT: Catalase; Cyt c: Cytochrome c; DA: Dopaminergic; DAMPs: Damage-associated molecular patterns; ETC: Electron transport chain; GPx: Glutathione peroxidase; GR: Glutathione reductase; GSH: Glutathione; HEP-2: Human epithelial cells; HI: Hypoxia ischemia; LED: Light-emitting diodes; LPS: Lipopolysaccharide; MB: Methylene blue; MCAO: Middle cerebral artery occlusion; MCU: Mitochondrial calcium uniporter complex; Mfn2: Mitofusin 2; MPTP: 1-methyl-4-phenyl-1,2,3,6-tetrahydropyridine;
}

mtDNA: Mitochondrial DNA; NFT: Neurofibrillary tangles; NO: Nitric oxide; NOS: Nitric oxide synthase; PBM: Photobiomodulation; PD: Parkinson's disease; PINK1: PTEN-induced kinase 1; PT: Photothrombotic; $\mathrm{p}$ tau: Hyperphosphorylated tau protein; ROS: Reactive oxygen species; SNc: Substantia nigra pars compacta; SOD: Superoxide dismutase; STZ: Streptozotocin; TBI: Traumatic brain injury; TNFa: Tumor necrosis factor alpha

\section{Acknowledgements}

Not applicable.

Authors' contributions

$L Y, H Y$, and $Q Z$ reviewed the literature and drafted the manuscript. $L Y$ and CW drew the figure. All authors read and approved the final manuscript.

\section{Funding}

This study was supported by research grants from the United States of America: NS086929 from the National Institute of Neurological Disorders and Stroke; NIA00051 from National Institute of Aging, National Institutes of Health; AHA00169 from American Heart Association;

Availability of data and materials

Not applicable.

Ethics approval and consent to participate

Not applicable.

\section{Consent for publication}

Not applicable.

\section{Competing interests}

The authors declare that they have no competing interests. 


\section{Author details}

'Department of Neuroscience and Regenerative Medicine, Medical College of Georgia, Augusta University, 1120 15th Street, Augusta, GA 30912, USA. 'Department of Cellular Biology and Anatomy, Medical College of Georgia, Augusta University, 1120 15th Street, Augusta, GA 30912, USA.

Received: 3 February 2020 Accepted: 6 May 2020

Published online: 01 June 2020

\section{References}

1. Chaturvedi RK, Flint BM. Mitochondrial diseases of the brain. Free Rad Biol Med. 2013;63:1-29.

2. Tian WF, Zeng S, Sheng $Q$, Chen JL, Weng P, Zhang XT, et al. Methylene Blue Protects the Isolated Rat Lungs from Ischemia-Reperfusion Injury by Attenuating Mitochondrial Oxidative Damage. Lung. 2018:196:73-82.

3. Szarka N, Pabbidi MR, Amrein K, Czeiter E, Berta G, Pohoczky K, et al. Traumatic Brain Injury Impairs Myogenic Constriction of Cerebral Arteries: Role of Mitochondria-Derived H2O2 and TRPV4-Dependent Activation of BKca Channels. J Neurotrauma. 2018.

4. Yang L, Tucker D, Dong Y, Wu C, Lu Y, Li Y, et al. Photobiomodulation therapy promotes neurogenesis by improving post-stroke local microenvironment and stimulating neuroprogenitor cells. Exp Neurol. 2018;299:86-96.

5. Niizuma K, Yoshioka H, Chen H, Kim GS, Jung JE, Katsu M, et al. Mitochondrial and apoptotic neuronal death signaling pathways in cerebral ischemia. Biochim Biophys Acta. 2010;1802:92-9.

6. Akbar M, Essa MM, Daradkeh G, Abdelmegeed MA, Choi Y, Mahmood L, et al. Mitochondrial dysfunction and cell death in neurodegenerative diseases through nitroxidative stress. Brain Res. 2016;1637:34-55.

7. Ahmed E, Donovan T, Yujiao L, Zhang Q. Mitochondrial Targeted Antioxidant in Cerebral Ischemia. J Neur Neurosci. 2015;6.

8. Lu Y, Wang R, Dong Y, Tucker D, Zhao N, Ahmed ME, et al. Low-level laser therapy for beta amyloid toxicity in rat hippocampus. Neurobiol Aging. 2017;49:165-82.

9. Ahmed ME, Tucker D, Dong Y, Lu Y, Zhao N, Wang R, et al. Methylene Blue promotes cortical neurogenesis and ameliorates behavioral deficit after photothrombotic stroke in rats. Neuroscience. 2016;336:39-48.

10. Bhat AH, Dar KB, Anees S, Zargar MA, Masood A, Sofi MA, et al. Oxidative stress, mitochondrial dysfunction and neurodegenerative diseases; a mechanistic insight. Biomed Pharmacother. 2015;74:101-10.

11. Chen X, Guo C, Kong J. Oxidative stress in neurodegenerative diseases. Neural Regeneration Res 2012;7:376-385.

12. Scaini G, Santos PM, Benedet J, Rochi N, Gomes LM, Borges LS, et al. Evaluation of Krebs cycle enzymes in the brain of rats after chronic administration of antidepressants. Brain Res Bull. 2010;82:224-7.

13. Streck EL, Goncalves CL, Furlanetto CB, Scaini G, Dal-Pizzol F, Quevedo J. Mitochondria and the central nervous system: searching for a pathophysiological basis of psychiatric disorders. Braz J Psychiatry. 2014;36: 156-67.

14. Marazziti D, Baroni S, Picchetti M, Landi P, Silvestri S, Vatteroni E, et al. Psychiatric disorders and mitochondrial dysfunctions. Eur Rev Med Pharmacol Sci. 2012;16:270-5

15. Johns DR. The other human genome: mitochondrial DNA and disease. Nat Med. 1996:2:1065-8.

16. Huang L, Lu J, Cerqueira B, Liu Y, Jiang Z, Duong TQ. Chronic oral methylene blue treatment in a rat model of focal cerebral ischemia/ reperfusion. Brain Res. 2018;1678:322-9.

17. Li L, Qin L, Lu HL, Li PJ, Song YJ, Yang RL. Methylene blue improves streptozotocin-induced memory deficit by restoring mitochondrial function in rats. Brain research. 2017;1657:208-14.

18. Fang Q, Yan X, Li S, Sun Y, Xu L, Shi Z, et al. Methylene Blue Ameliorates Ischemia/Reperfusion-Induced Cerebral Edema: An MRI and Transmission Electron Microscope Study. Acta Neurochirurgica Suppl. 2016;121:227-36.

19. Hosokawa M, Arai T, Masuda-Suzukake M, Nonaka T, Yamashita M, Akiyama $\mathrm{H}$, et al. Methylene blue reduced abnormal tau accumulation in P301L tau transgenic mice. PloS One. 2012;7:e52389.

20. Necula M, Breydo L, Milton S, Kayed R, van der Veer WE, Tone P, et al. Methylene blue inhibits amyloid Abeta oligomerization by promoting fibrillization. Biochemistry. 2007:46:8850-60.

21. Marazziti D, Baroni S, Picchetti M, Landi P, Silvestri S, Vatteroni E, et al. Mitochondrial alterations and neuropsychiatric disorders. Curr Med Chem. 2011;18:4715-21.
22. Tucker D, Lu Y, Zhang Q. From Mitochondrial Function to Neuroprotectionan Emerging Role for Methylene Blue. Mol Neurobiol. 2018;55:5137-53.

23. Berry EA, Guergova-Kuras M, Huang LS, Crofts AR. Structure and function of cytochrome bc complexes. Ann Rev Biochem. 2000;69:1005-75.

24. Neustadt J, Pieczenik SR. Medication-induced mitochondrial damage and disease. Mol Nutr Food Res. 2008:52:780-8.

25. Hunter DJ, Oganesyan VS, Salerno JC, Butler CS, Ingledew WJ, Thomson AJ. Angular dependences of perpendicular and parallel mode electron paramagnetic resonance of oxidized beef heart cytochrome c oxidase. Biophys J. 2000;78:439-50.

26. Bonda DJ, Wang X, Lee HG, Smith MA, Perry G, Zhu X. Neuronal failure in Alzheimer's disease: a view through the oxidative stress looking-glass. Neurosci Bull. 2014:30:243-52.

27. Wang X, Wang W, Li L, Perry G, Lee HG, Zhu X. Oxidative stress and mitochondrial dysfunction in Alzheimer's disease. Biochimica Biophysica Acta. 2014;1842:1240-7.

28. Wang X, Su B, Lee HG, Li X, Perry G, Smith MA, et al. Impaired balance of mitochondrial fission and fusion in Alzheimer's disease. J Neurosci. 2009;29: 9090-103.

29. Hirai K, Aliev G, Nunomura A, Fujioka H, Russell RL, Atwood CS, et al. Mitochondrial abnormalities in Alzheimer's disease. J Neurosci. 2001;21: 3017-23.

30. Manczak M, Calkins MJ, Reddy PH. Impaired mitochondrial dynamics and abnormal interaction of amyloid beta with mitochondrial protein Drp1 in neurons from patients with Alzheimer's disease: implications for neuronal damage. Hum Mol Genet. 2011;20:2495-509.

31. Reddy PH, Beal MF. Amyloid beta, mitochondrial dysfunction and synaptic damage: implications for cognitive decline in aging and Alzheimer's disease Trends Mol Med. 2008;14:45-53.

32. Gibson GE, Sheu KF, Blass JP. Abnormalities of mitochondrial enzymes in Alzheimer disease. J Neural Transm (Vienna). 1998;105:855-70

33. Gold M, Alderton C, Zvartau-Hind M, Egginton S, Saunders AM, Irizarry M, et al. Rosiglitazone monotherapy in mild-to-moderate Alzheimer's disease: results from a randomized, double-blind, placebo-controlled phase III study. Dementia Geriatr Cogn Disord. 2010;30:131-46.

34. Maurer I, Zierz S, Moller HJ. A selective defect of cytochrome c oxidase is present in brain of Alzheimer disease patients. Neurobiol Aging. 2000;21:455-62.

35. Parker WD Jr, Filley CM, Parks JK. Cytochrome oxidase deficiency in Alzheimer's disease. Neurology. 1990;40:1302-3.

36. Coskun PE, Beal MF, Wallace DC. Alzheimer's brains harbor somatic mtDNA control-region mutations that suppress mitochondrial transcription and replication. Proc Natl Acad Sci U S A. 2004;101:10726-31.

37. Caspersen C, Wang N, Yao J, Sosunov A, Chen X, Lustbader JW, et al. Mitochondrial Abeta: a potential focal point for neuronal metabolic dysfunction in Alzheimer's disease. Faseb J. 2005;19:2040-1.

38. Wilkins HM, Swerdlow RH. Relationships Between Mitochondria and Neuroinflammation: Implications for Alzheimer's Disease. Curr Topics Med Chem. 2016;16:849-57.

39. Wilkins HM, Carl SM, Weber SG, Ramanujan SA, Festoff BW, Linseman DA et al. Mitochondrial lysates induce inflammation and Alzheimer's diseaserelevant changes in microglial and neuronal cells. J Alzheimer's Dis. 2015;45: 305-18.

40. Onyango IG, Dennis J, Khan SM. Mitochondrial Dysfunction in Alzheimer's Disease and the Rationale for Bioenergetics Based Therapies. Aging Dis. 2016;7:201-14

41. Eckert A, Keil U, Marques CA, Bonert A, Frey C, Schussel K, et al. Mitochondrial dysfunction, apoptotic cell death, and Alzheimer's disease. Biochem Pharmacol. 2003;66:1627-34.

42. Jadiya P, Kolmetzky DW, Tomar D, Di Meco A, Lombardi AA, Lambert JP, et al. Impaired mitochondrial calcium efflux contributes to disease progression in models of Alzheimer's disease. Nat Commun. 2019;10:3885.

43. Magi S, Castaldo P, Macri ML, Maiolino M, Matteucci A, Bastioli G, et al. Intracellular Calcium Dysregulation: Implications for Alzheimer's Disease. Biomed Res Int 2016:2016:6701324.

44. Sanz-Blasco S, Valero RA, Rodriguez-Crespo I, Villalobos C, Nunez L. Mitochondrial Ca2+ overload underlies Abeta oligomers neurotoxicity providing an unexpected mechanism of neuroprotection by NSAIDs. PloS One. 2008:3:e2718.

45. Lee SH, Kim MH, Lee JY, Lee D, Park KH, Ho WK. Na+/Ca2+ exchange and $\mathrm{Ca} 2+$ homeostasis in axon terminals of mammalian central neurons. Ann N Y Acad Sci. 2007;1099:396-412. 
46. Cheng Y, Bai F. The Association of Tau With Mitochondrial Dysfunction in Alzheimer's Disease. Front Neurosci. 2018;12:163.

47. Devi L, Anandatheerthavarada HK. Mitochondrial trafficking of APP and alpha synuclein: Relevance to mitochondrial dysfunction in Alzheimer's and Parkinson's diseases. Biochimica Biophysica Acta. 2010;1802:11-9.

48. Fang EF. Mitophagy and $\mathrm{NAD}(+)$ inhibit Alzheimer disease. Autophagy. 2019;15:1112-4

49. Fang EF, Hou Y, Palikaras K, Adriaanse BA, Kerr JS, Yang B, et al. Mitophagy inhibits amyloid-beta and tau pathology and reverses cognitive deficits in models of Alzheimer's disease. Nat Neurosci. 2019;22:401-12.

50. Pandya JD, Nukala VN, Sullivan PG. Concentration dependent effect of calcium on brain mitochondrial bioenergetics and oxidative stress parameters. Front Neuroenerget. 2013;5:10.

51. Zhang L, Wang H, Zhou X, Mao L, Ding K, Hu Z. Role of mitochondrial calcium uniporter-mediated $\mathrm{Ca}(2+)$ and iron accumulation in traumatic brain injury. J Cell Mol Med. 2019;23:2995-3009.

52. Harris LK, Black RT, Golden KM, Reeves TM, Povlishock JT, Phillips LL. Traumatic brain injury-induced changes in gene expression and functional activity of mitochondrial cytochrome C oxidase. J Neurotrauma. 2001;18:993-1009.

53. Fischer TD, Hylin MJ, Zhao J, Moore AN, Waxham MN, Dash PK. Altered Mitochondrial Dynamics and TBI Pathophysiology. Front Syst Neurosci. 2016; 10:29

54. Knott $A B$, Bossy-Wetzel E. Impairing the mitochondrial fission and fusion balance: a new mechanism of neurodegeneration. Ann N Y Acad Sci. 2008; 1147:283-92.

55. Detmer SA, Chan DC. Functions and dysfunctions of mitochondrial dynamics. Nat Rev Mol Cell Biol. 2007;8:870-9.

56. Chen $\mathrm{H}$, Chomyn A, Chan DC. Disruption of fusion results in mitochondrial heterogeneity and dysfunction. J Biol Chem. 2005;280:26185-92.

57. Rintoul GL, Filiano AJ, Brocard JB, Kress GJ, Reynolds IJ. Glutamate decreases mitochondrial size and movement in primary forebrain neurons. J Neurosci. 2003; $23: 7881-8$

58. Sen N. Aberrant cell cycle induction is pivotal for mitochondrial biogenesis after traumatic brain injury. Neural Regen Res. 2019;14:1215-6.

59. Dharmasaroja PA. Fluid Intake Related to Brain Edema in Acute Middle Cerebral Artery Infarction. Transl Stroke Res. 2016;7:49-53.

60. Hofmeijer J, van Putten MJ. Ischemic cerebral damage: an appraisal of synaptic failure. Stroke. 2012:43:607-15.

61. Lee JM, Grabb MC, Zipfel GJ, Choi DW. Brain tissue responses to ischemia. J Clin Invest. 2000;106:723-31.

62. Brookes PS, Yoon Y, Robotham JL, Anders MW, Sheu SS. Calcium, ATP, and ROS: a mitochondrial love-hate triangle. Am J Physiol Cell Physiol. 2004;287: C817-33.

63. Cavallucci V, Bisicchia E, Cencioni MT, Ferri A, Latini L, Nobili A, et al. Acute focal brain damage alters mitochondrial dynamics and autophagy in axotomized neurons. Cell Death Dis. 2014;5:e1545.

64. Bedard K, Krause KH. The NOX family of ROS-generating NADPH oxidases: physiology and pathophysiology. Physiol Rev. 2007:87:245-313.

65. Li P, Nijhawan D, Budihardjo I, Srinivasula SM, Ahmad M, Alnemri ES, et al. Cytochrome $\mathrm{c}$ and dATP-dependent formation of Apaf-1/caspase-9 complex initiates an apoptotic protease cascade. Cell. 1997;91:479-89.

66. Sims NR, Muyderman H. Mitochondria, oxidative metabolism and cell death in stroke. Biochimica Biophysica Acta. 2010:1802, 80-91.

67. Chouchani ET, Pell VR, James AM, Work LM, Saeb-Parsy K, Frezza C, et al. A Unifying Mechanism for Mitochondrial Superoxide Production during Ischemia-Reperfusion Injury. Cell Metab. 2016;23:254-63.

68. Genova ML, Pich MM, Bernacchia A, Bianchi C, Biondi A, Bovina C, et al. The mitochondrial production of reactive oxygen species in relation to aging and pathology. Ann N Y Acad Sci. 2004;1011:86-100.

69. Griffiths EJ, Halestrap AP. Mitochondrial non-specific pores remain closed during cardiac ischaemia, but open upon reperfusion. Biochem J. 1995; 307(Pt 1):93-8

70. Peng C, Rao W, Zhang L, Wang K, Hui H, Wang L, et al. Mitofusin 2 ameliorates hypoxia-induced apoptosis via mitochondrial function and signaling pathways. Int J Biochem Cell Biol. 2015;69:29-40.

71. Martorell-Riera A, Segarra-Mondejar M, Munoz JP, Ginet V, Olloquequi J, PerezClausell J, et al. Mfn2 downregulation in excitotoxicity causes mitochondrial dysfunction and delayed neuronal death. EMBO J. 2014;33:2388-407.

72. Barsoum MJ, Yuan H, Gerencser AA, Liot G, Kushnareva Y, Graber S, et al. Nitric oxide-induced mitochondrial fission is regulated by dynamin-related GTPases in neurons. EMBO J. 2006;25:3900-11.
73. Liu W, Tian F, Kurata T, Morimoto N, Abe K. Dynamic changes of mitochondrial fusion and fission proteins after transient cerebral ischemia in mice. J Neurosci Res. 2012;90:1183-9.

74. Owens K, Park JH, Gourley S, Jones H, Kristian T. Mitochondrial dynamics: cell-type and hippocampal region specific changes following global cerebral ischemia. J Bioenerg Biomembr. 2015;47:13-31.

75. Shi RY, Zhu SH, Li V, Gibson SB, Xu XS, Kong JM. BNIP3 interacting with LC3 triggers excessive mitophagy in delayed neuronal death in stroke. Cns Neurosci Ther. 2014;20:1045-55.

76. Zuo W, Zhang S, Xia CY, Guo XF, He WB, Chen NH. Mitochondria autophagy is induced after hypoxic/ischemic stress in a Drp1 dependent manner: the role of inhibition of Drp1 in ischemic brain damage. Neuropharmacology. 2014:86:103-15.

77. Li Q, Zhang T, Wang J, Zhang Z, Zhai Y, Yang GY, et al. Rapamycin attenuates mitochondrial dysfunction via activation of mitophagy in experimental ischemic stroke. Biochem Biophys Res Commun. 2014;444: $182-8$.

78. Allen J, Romay-Tallon R, Brymer KJ, Caruncho HJ, Kalynchuk LE. Mitochondria and Mood: Mitochondrial Dysfunction as a Key Player in the Manifestation of Depression. Front Neurosci. 2018;12:386.

79. Rezin GT, Amboni G, Zugno Al, Quevedo J, Streck EL. Mitochondrial dysfunction and psychiatric disorders. Neurochem Res. 2009;34:1021-9.

80. Gardner A, Johansson A, Wibom R, Nennesmo I, von Dobeln U, Hagenfeldt $L$, et al. Alterations of mitochondrial function and correlations with personality traits in selected major depressive disorder patients. J Affect Disord. 2003;76:55-68

81. Gong $Y$, Chai $Y$, Ding JH, Sun $X L, H u$ G. Chronic mild stress damages mitochondrial ultrastructure and function in mouse brain. Neurosci Letters. 2011:488:76-80.

82. Rezin GT, Goncalves CL, Daufenbach JF, Fraga DB, Santos PM, Ferreira GK, et al. Acute administration of ketamine reverses the inhibition of mitochondrial respiratory chain induced by chronic mild stress. Brain Res Bull. 2009;79:418-21

83. Rezin GT, Cardoso MR, Goncalves CL, Scaini G, Fraga DB, Riegel RE, et al Inhibition of mitochondrial respiratory chain in brain of rats subjected to an experimental model of depression. Neurochem Int. 2008;53:395-400.

84. Gamaro GD, Streck EL, Matte C, Prediger ME, Wyse AT, Dalmaz C. Reduction of hippocampal $\mathrm{Na}+, \mathrm{K}+-$ ATPase activity in rats subjected to an experimental model of depression. Neurochem Res. 2003;28:1339-44.

85. Madrigal JL, Olivenza R, Moro MA, Lizasoain I, Lorenzo P, Rodrigo J, et al. Glutathione depletion, lipid peroxidation and mitochondrial dysfunction are induced by chronic stress in rat brain. Neuropsychopharmacology. 2001:24:420-9.

86. Wang X, Sundquist K, Rastkhani H, Palmer K, Memon AA, Sundquist J. Association of mitochondrial DNA in peripheral blood with depression, anxiety and stress- and adjustment disorders in primary health care patients. Eur Neuropsychopharmacol. 2017;27:751-8.

87. Veronese N, Stubbs B, Solmi M, Vaona A, Demurtas J, Carvalho AF, et al. Mitochondrial genetic haplogroups and depressive symptoms: A large study among people in North America. J Affect Disord. 2017;217:55-9.

88. Tobe EH. Mitochondrial dysfunction, oxidative stress, and major depressive disorder. Neuropsychiatr Dis Treat. 2013;9:567-73.

89. Czarny P, Kwiatkowski D, Kacperska D, Kawczynska D, Talarowska M, Orzechowska A, et al. Elevated level of DNA damage and impaired repair of oxidative DNA damage in patients with recurrent depressive disorder. Med Sci Monitor. 2015;21:412-8.

90. Bose A, Beal MF. Mitochondrial dysfunction in Parkinson's disease. J Neurochem. 2016;139(Suppl 1):216-31.

91. Grunewald A, Rygiel KA, Hepplewhite PD, Morris CM, Picard M, Turnbull DM. Mitochondrial DNA Depletion in Respiratory Chain-Deficient Parkinson Disease Neurons. Ann Neurol. 2016;79:366-78.

92. Lin MT, Beal MF. Mitochondrial dysfunction and oxidative stress in neurodegenerative diseases. Nature. 2006;443:787-95.

93. Lill CM. Genetics of Parkinson's disease. Mol Cell Probes. 2016;30:386-96.

94. Coxhead J, Kurzawa-Akanbi M, Hussain R, Pyle A, Chinnery P, Hudson G. Somatic mtDNA variation is an important component of Parkinson's disease. Neurobiol Aging. 2016;38(217):e211-7 e216.

95. Pyle A, Anugrha H, Kurzawa-Akanbi M, Yarnall A, Burn D, Hudson G. Reduced mitochondrial DNA copy number is a biomarker of Parkinson's disease. Neurobiol Aging. 2016;38(216):e217-6 e210.

96. Dauer W, Przedborski S. Parkinson's disease: mechanisms and models. Neuron. 2003;39:889-909. 
97. Puspita L, Chung SY, Shim JW. Oxidative stress and cellular pathologies in Parkinson's disease. Mol Brain. 2017;10:53.

98. Berthet A, Margolis EB, Zhang J, Hsieh I, Hnasko TS, Ahmad J, et al. Loss of mitochondrial fission depletes axonal mitochondria in midbrain dopamine neurons. J Neurosci. 2014;34:14304-17.

99. Scarffe LA, Stevens DA, Dawson VL, Dawson TM. Parkin and PINK1: much more than mitophagy. Trends Neurosci. 2014;37:315-24.

100. Zhang Z, Liu L, Jiang X, Zhai S, Xing D. The Essential Role of Drp1 and Its Regulation by S-Nitrosylation of Parkin in Dopaminergic Neurodegeneration: Implications for Parkinson's Disease. Antioxid Redox Signal. 2016;25:609-22.

101. Lee KS, Huh S, Lee S, Wu Z, Kim AK, Kang HY, et al. Altered ER-mitochondria contact impacts mitochondria calcium homeostasis and contributes to neurodegeneration in vivo in disease models. Proc Natl Acad Sci U S A. 2018;115:E8844-53.

102. Soman SK, Bazala M, Keatinge M, Bandmann O, Kuznicki J. Restriction of mitochondrial calcium overload by mcu inactivation renders a neuroprotective effect in zebrafish models of Parkinson's disease. Biol Open. 2019;8.

103. Choong CJ, Mochizuki H. Inappropriate trafficking of damaged mitochondria in Parkinson's disease. Stem Cell Invest. 2017;4:17.

104. Gao F, Yang J, Wang D, Li C, Fu Y, Wang H, et al. Mitophagy in Parkinson's Disease: Pathogenic and Therapeutic Implications. Front Neurol. 2017;8:527.

105. Reddy PH, Oliver DM. Amyloid Beta and Phosphorylated Tau-Induced Defective Autophagy and Mitophagy in Alzheimer's Disease. Cells. 2019;8.

106. Tang J, Oliveros A, Jang MH. Dysfunctional Mitochondrial Bioenergetics and Synaptic Degeneration in Alzheimer Disease. Int Neurourol J. 2019;23:S5-10.

107. Reddy PH, McWeeney S, Park BS, Manczak M, Gutala RV, Partovi D, et al. Gene expression profiles of transcripts in amyloid precursor protein transgenic mice: up-regulation of mitochondrial metabolism and apoptotic genes is an early cellular change in Alzheimer's disease. Hum Mol Genet. 2004;13:1225-40.

108. Lin MT, Simon DK, Ahn CH, Kim LM, Beal MF. High aggregate burden of somatic mtDNA point mutations in aging and Alzheimer's disease brain. Hum Mol Genet. 2002;11:133-45.

109. Guo C, Sun L, Chen X, Zhang D. Oxidative stress, mitochondrial damage and neurodegenerative diseases. Neural Regen Res. 2013;8:2003-14.

110. Finkel T, Holbrook NJ. Oxidants, oxidative stress and the biology of ageing. Nature. 2000;408:239-47.

111. Ristow M, Schmeisser K. Mitohormesis: Promoting Health and Lifespan by Increased Levels of Reactive Oxygen Species (ROS). Dose-Response. 2014;12: 288-341.

112. Valko M, Leibfritz D, Moncol J, Cronin MT, Mazur M, Telser J. Free radicals and antioxidants in normal physiological functions and human disease. Int J Biochem Cell Biol. 2007;39:44-84

113. Mittler R, Vanderauwera S, Suzuki N, Miller G, Tognetti VB, Vandepoele K, et al. ROS signaling: the new wave? Trends Plant Sci. 2011;16:300-9.

114. Ristow M. Unraveling the truth about antioxidants: mitohormesis explains ROS-induced health benefits. Nat Med. 2014;20:709-11.

115. Gorjao R, Takahashi HK, Pan JA, Massao HS. Molecular mechanisms involved in inflammation and insulin resistance in chronic diseases and possible interventions. J Biomed Biotechnol. 2012;2012:841983.

116. Beckman KB, Ames BN. Endogenous oxidative damage of mtDNA. Mutation Res. 1999;424:51-8.

117. Rugarli El, Langer T. Mitochondrial quality control: a matter of life and death for neurons. EMBO J. 2012;31:1336-49.

118. Bhatti JS, Bhatti GK, Reddy PH. Mitochondrial dysfunction and oxidative stress in metabolic disorders - A step towards mitochondria based therapeutic strategies. Biochimica Biophysica Acta Mol Basis Dis. 2017;1863: 1066-77.

119. Martin M, Macias M, Escames G, Reiter RJ, Agapito MT, Ortiz GG, et al. Melatonin-induced increased activity of the respiratory chain complexes I and IV can prevent mitochondrial damage induced by ruthenium red in vivo. J Pineal Res. 2000;28:242-8.

120. Baughman JM, Perocchi F, Girgis HS, Plovanich M, Belcher-Timme CA, Sancak $Y$, et al. Integrative genomics identifies MCU as an essential component of the mitochondrial calcium uniporter. Nature. 2011;476:341-5.

121. Bertolini MS, Chiurillo MA, Lander N, Vercesi AE, Docampo R. MICU1 and MICU2 Play an Essential Role in Mitochondrial Ca (2+) Uptake, Growth, and Infectivity of the Human Pathogen Trypanosoma cruzi. mBio. 2019:10.

122. Vos M, Lauwers $E$, Verstreken P. Synaptic mitochondria in synaptic transmission and organization of vesicle pools in health and disease. Front Synaptic Neurosci. 2010;2:139.
123. Bianchi K, Rimessi A, Prandini A, Szabadkai G, Rizzuto R. Calcium and mitochondria: mechanisms and functions of a troubled relationship. Biochim Biophysica Acta. 2004;1742:119-31.

124. Feno S, Butera G, Vecellio Reane D, Rizzuto R, Raffaello A. Crosstalk between Calcium and ROS in Pathophysiological Conditions. Oxid Med Cell Longev. 2019:9324018.

125. Bertero E, Maack C. Calcium Signaling and Reactive Oxygen Species in Mitochondria. Circ Res. 2018;122:1460-78.

126. Marchi S, Pinton P. The mitochondrial calcium uniporter complex: molecular components, structure and physiopathological implications. J Physiol. 2014; 592:829-39.

127. Wang Y, Nartiss Y, Steipe B, McQuibban GA, Kim PK. ROS-induced mitochondrial depolarization initiates PARK2/PARKIN-dependent mitochondrial degradation by autophagy. Autophagy. 2012;8:1462-76.

128. Kerr JS, Adriaanse BA, Greig NH, Mattson MP, Cader MZ, Bohr VA, et al. Mitophagy and Alzheimer's Disease: Cellular and Molecular Mechanisms. Trends Neurosci. 2017:40:151-66.

129. Jin SM, Youle RJ. The accumulation of misfolded proteins in the mitochondrial matrix is sensed by PINK1 to induce PARK2/Parkin-mediated mitophagy of polarized mitochondria. Autophagy. 2013;9:1750-7.

130. Wang Y, Liu N, Lu B. Mechanisms and roles of mitophagy in neurodegenerative diseases. Cns Neurosci Ther. 2019;25:859-75.

131. Martin-Maestro P, Gargini R, Garcia E, Simon D, Avila J, Garcia-Escudero V. Mitophagy Failure in APP and Tau Overexpression Model of Alzheimer's Disease. J Alzheimer's Dis. 2019;70:525-40.

132. Shefa U, Jeong NY, Song IO, Chung HJ, Kim D, Jung J, et al. Mitophagy links oxidative stress conditions and neurodegenerative diseases. Neural Regen Res. 2019;14:749-56.

133. Yang S, Xia C, Li S, Du L, Zhang L, Zhou R. Defective mitophagy driven by dysregulation of rheb and KIF5B contributes to mitochondrial reactive oxygen species (ROS)-induced nod-like receptor 3 (NLRP3) dependent proinflammatory response and aggravates lipotoxicity. Redox Biol. 2014;3: $63-71$.

134. Seo AY, Joseph AM, Dutta D, Hwang JC, Aris JP, Leeuwenburgh C. New insights into the role of mitochondria in aging: mitochondrial dynamics and more. J Cell Sci. 2010;123:2533-42.

135. Yang L, Dong Y, Wu C, Li Y, Guo Y, Yang B, et al. Photobiomodulation preconditioning prevents cognitive impairment in a neonatal rat model of hypoxia-ischemia. J Biophotonics. 2019;12:e201800359.

136. Wu S, Zhou F, Zhang Z, Xing D. Mitochondrial oxidative stress causes mitochondrial fragmentation via differential modulation of mitochondrial fission-fusion proteins. Febs J. 2011;278:941-54.

137. Park J, Choi H, Min JS, Park SJ, Kim JH, Park HJ, et al. Mitochondrial dynamics modulate the expression of pro-inflammatory mediators in microglial cells. J Neurochem. 2013;127:221-32.

138. van Horssen J, van Schaik P, Witte M. Inflammation and mitochondrial dysfunction: A vicious circle in neurodegenerative disorders? Neurosci Letters. 2019;710:132931.

139. Breda CNS, Davanzo GG, Basso PJ, Saraiva Camara NO, Moraes-Vieira PMM Mitochondria as central hub of the immune system. Redox Biol. 2019;26:101255.

140. Banoth B, Cassel SL. Mitochondria in innate immune signaling. Transl Res. 2018;202:52-68

141. Weinberg SE, Sena LA, Chandel NS. Mitochondria in the regulation of innate and adaptive immunity. Immunity. 2015;42:406-17.

142. Zhou R, Yazdi AS, Menu P, Tschopp J. A role for mitochondria in NLRP3 inflammasome activation. Nature. 2011;469:221-5.

143. Land WG. The Role of Damage-Associated Molecular Patterns (DAMPs) in Human Diseases: Part II: DAMPs as diagnostics, prognostics and therapeutics in clinical medicine. Sultan Qaboos Univ Med J. 2015;15:e157-70.

144. West AP, Shadel GS, Ghosh S. Mitochondria in innate immune responses. Nat Rev Immunol. 2011;11:389-402.

145. Zhao XY, Lu MH, Yuan DJ, Xu DE, Yao PP, Ji WL, et al. Mitochondrial Dysfunction in Neural Injury. Front Neurosci. 2019;13:30.

146. Vringer E, Tait SWG. Mitochondria and Inflammation: Cell Death Heats Up. Front Cell Dev Biol. 2019;7:100.

147. Yu EP, Bennett MR. Mitochondrial DNA damage and atherosclerosis. Trends Endocrinol Metab. 2014;25:481-7.

148. Nakahira K, Haspel JA, Rathinam VA, Lee SJ, Dolinay T, Lam HC, et al. Autophagy proteins regulate innate immune responses by inhibiting the release of mitochondrial DNA mediated by the NALP3 inflammasome. Nat Immunol. 2011;12:222-30. 
149. Motori E, Puyal J, Toni N, Ghanem A, Angeloni C, Malaguti M, et al. Inflammation-induced alteration of astrocyte mitochondrial dynamics requires autophagy for mitochondrial network maintenance. Cell Metab. 2013;18:844-59.

150. Chen XH, Zhao YP, Xue M, Ji CB, Gao CL, Zhu JG, et al. TNF-alpha induces mitochondrial dysfunction in 3T3-L1 adipocytes. Mol Cell Endocrinol. 2010; 328:63-9.

151. Prajapati $P$, Sripada $L$, Singh $K$, Bhatelia K, Singh R. TNF-alpha regulates miRNA targeting mitochondrial complex-I and induces cell death in dopaminergic cells. Biochimica Biophysica Acta. 2015;1852:451-61.

152. Swerdlow RH. Pathogenesis of Alzheimer's disease. Clin Interv Aging. 2007;2: 347-59.

153. LaFerla FM, Green KN, Oddo S. Intracellular amyloid-beta in Alzheimer's disease. Nat Rev Neurosci. 2007;8:499-509.

154. Reddy PH, Manczak M, Yin X. Mitochondria-Division Inhibitor 1 Protects Against Amyloid-beta induced Mitochondrial Fragmentation and Synaptic Damage in Alzheimer's Disease. J Alzheimer's Dis. 2017:58:147-62.

155. Fukuyama H, Ogawa M, Yamauchi H, Yamaguchi S, Kimura J, Yonekura Y, et al. Altered cerebral energy metabolism in Alzheimer's disease: a PET study. J Nuclear Med. 1994;35:1-6.

156. Friedland RP, Budinger TF, Ganz E, Yano Y, Mathis CA, Koss B, et al. Regional cerebral metabolic alterations in dementia of the Alzheimer type: positron emission tomography with [18F]fluorodeoxyglucose. J Comp Assist Tomography. 1983;7:590-8.

157. Frackowiak RS, Pozzilli C, Legg NJ, Du Boulay GH, Marshall J, Lenzi GL, et al. Regional cerebral oxygen supply and utilization in dementia. A clinical and physiological study with oxygen-15 and positron tomography. Brain. 1981; 104:753-78.

158. Wu C, Yang L, Tucker D, Dong Y, Zhu L, Duan R, et al. Beneficial Effects of Exercise Pretreatment in a Sporadic Alzheimer's Rat Model. Med Sci Sports Exerc. 2018;50:945-56.

159. Pavlov PF, Hansson Petersen C, Glaser E, Ankarcrona M. Mitochondrial accumulation of APP and Abeta: significance for Alzheimer disease pathogenesis. J Cell Mol Med. 2009;13:4137-45.

160. Gabuzda D, Busciglio J, Chen LB, Matsudaira P, Yankner BA. Inhibition of energy metabolism alters the processing of amyloid precursor protein and induces a potentially amyloidogenic derivative. J Biol Chem. 1994;269:13623-8.

161. Khan SM, Cassarino DS, Abramova NN, Keeney PM, Borland MK, Trimmer PA et al. Alzheimer's disease cybrids replicate beta-amyloid abnormalities through cell death pathways. Ann Neurol. 2000;48:148-55.

162. Schneier AJ, Shields BJ, Hostetler SG, Xiang H, Smith GA. Incidence of pediatric traumatic brain injury and associated hospital resource utilization in the United States. Pediatrics. 2006;118:483-92.

163. Hiebert JB, Shen Q, Thimmesch AR, Pierce JD. Traumatic brain injury and mitochondrial dysfunction. Am J Med Sci. 2015;350:132-8.

164. Cheng G, Kong RH, Zhang LM, Zhang JN. Mitochondria in traumatic brain injury and mitochondrial-targeted multipotential therapeutic strategies. $\mathrm{Br}$ J Pharmacol. 2012;167:699-719.

165. Ertel EA, Campbell KP, Harpold MM, Hofmann F, Mori Y, Perez-Reyes E, et al. Nomenclature of voltage-gated calcium channels. Neuron. 2000;25:533-5.

166. Starkov AA, Chinopoulos C, Fiskum G. Mitochondrial calcium and oxidative stress as mediators of ischemic brain injury. Cell Calcium. 2004;36:257-64.

167. Mozaffarian D, Benjamin EJ, Go AS, Arnett DK, Blaha MJ, Cushman M, et al. Heart Disease and Stroke Statistics-2016 Update: A Report From the American Heart Association. Circulation. 2016;133:e38-360.

168. Liu F, Lu J, Manaenko A, Tang J, Hu Q. Mitochondria in Ischemic Stroke: New Insight and Implications. Aging Dis. 2018:9:924-37.

169. Lapchak PA, Zhang JH. The High Cost of Stroke and Stroke Cytoprotection Research. Transl Stroke Res. 2017:8:307-17.

170. Krantic S, Mechawar N, Reix S, Quirion R. Apoptosis-inducing factor: a matter of neuron life and death. Prog Neurobiol. 2007:81:179-96.

171. Qi Z, Dong W, Shi W, Wang R, Zhang C, Zhao Y, et al. BCl-2 phosphorylation triggers autophagy switch and reduces mitochondrial damage in limb remote ischemic conditioned rats after ischemic stroke. Transl Stroke Res. 2015;6:198-206.

172. Baek SH, Noh AR, Kim KA, Akram M, Shin YJ, Kim ES, et al. Modulation of mitochondrial function and autophagy mediates carnosine neuroprotection against ischemic brain damage. Stroke. 2014;45:2438-43.

173. Zhang X, Yan H, Yuan Y, Gao J, Shen Z, Cheng Y, et al. Cerebral ischemiareperfusion-induced autophagy protects against neuronal injury by mitochondrial clearance. Autophagy. 2013;9:1321-33.
174. Powers WJ, Zazulia AR, Videen TO, Adams RE, Yundt KD, Aiyagari V, et al. Autoregulation of cerebral blood flow surrounding acute (6 to 22 hours) intracerebral hemorrhage. Neurology. 2001;57:18-24.

175. Zazulia AR, Diringer MN, Videen TO, Adams RE, Yundt K, Aiyagari V, et al. Hypoperfusion without ischemia surrounding acute intracerebral hemorrhage. J Cerebral Blood Flow Metab. 2001;21:804-10.

176. Mayer SA, Lignelli A, Fink ME, Kessler DB, Thomas CE, Swarup R, et al. Perilesional blood flow and edema formation in acute intracerebral hemorrhage: a SPECT study. Stroke. 1998;29:1791-8.

177. Kim-Han JS, Kopp SJ, Dugan LL, Diringer MN. Perihematomal mitochondrial dysfunction after intracerebral hemorrhage. Stroke. 2006;37:2457-62.

178. Hall CN, Klein-Flugge MC, Howarth C, Attwell D. Oxidative phosphorylation, not glycolysis, powers presynaptic and postsynaptic mechanisms underlying brain information processing. J Neurosci. 2012;32:8940-51.

179. Bansal Y, Kuhad A. Mitochondrial Dysfunction in Depression. Curr Neuropharmacol. 2016;14:610-8.

180. Baxter LR Jr, Schwartz JM, Phelps ME, Mazziotta JC, Guze BH, Selin CE, et al. Reduction of prefrontal cortex glucose metabolism common to three types of depression. Arch Gen Psychiatr. 1989;46:243-50.

181. Videbech P. PET measurements of brain glucose metabolism and blood flow in major depressive disorder: a critical review. Acta Psychiatr Scand. 2000;101:11-20.

182. Gardner A, Salmaso D, Nardo D, Micucci F, Nobili F, Sanchez-Crespo A, et al Mitochondrial function is related to alterations at brain SPECT in depressed patients. CNS Spectrums. 2008;13:805-14.

183. Chang CC, Jou SH, Lin TT, Lai TJ, Liu CS. Mitochondria DNA change and oxidative damage in clinically stable patients with major depressive disorder. PloS One. 2015;10:e0125855.

184. Adzic M, Brkic Z, Bulajic S, Mitic M, Radojcic MB. Antidepressant Action on Mitochondrial Dysfunction in Psychiatric Disorders. Drug Dev Res. 2016;77:400-6.

185. Wang Q, Dwivedi Y. Transcriptional profiling of mitochondria associated genes in prefrontal cortex of subjects with major depressive disorder. World J Biol Psychiatr. 2017;18:592-603.

186. Bajpai A, Verma AK, Srivastava M, Srivastava R. Oxidative stress and major depression. J Clin Diagn Res. 2014;8:CCO4-7.

187. Grases G, Colom MA, Fernandez RA, Costa-Bauza A, Grases F. Evidence of higher oxidative status in depression and anxiety. Oxid Med Cell Longev. 2014;2014:430216.

188. Michel TM, Pulschen D, Thome J. The role of oxidative stress in depressive disorders. Curr Pharm Des. 2012;18:5890-9.

189. Jankovic J. Parkinson's disease: clinical features and diagnosis. J Neurol Neurosurg Psychiatr. 2008;79:368-76.

190. Betarbet R, Sherer TB, MacKenzie G, Garcia-Osuna M, Panov AV, Greenamyre JT. Chronic systemic pesticide exposure reproduces features of Parkinson's disease. Nat Neurosci. 2000:3:1301-6.

191. Chaturvedi RK, Beal MF. Mitochondrial approaches for neuroprotection. Ann N Y Acad Sci. 2008;1147:395-412.

192. Ginimuge PR, Jyothi SD. Methylene blue: revisited. J Anaesth Clin Pharmacol. 2010;26:517-20.

193. Schirmer RH, Adler H, Pickhardt M, Mandelkow E. "Lest we forget you-methylene blue...". Neurobiology of aging. 2011:32:2325 e2327-2316.

194. Deiana S, Harrington CR, Wischik CM, Riedel G. Methylthioninium chloride reverses cognitive deficits induced by scopolamine: comparison with rivastigmine. Psychopharmacology (Berl). 2009;202:53-65.

195. Riha PD, Bruchey AK, Echevarria DJ, Gonzalez-Lima F. Memory facilitation by methylene blue: dose-dependent effect on behavior and brain oxygen consumption. Eur J Pharmacol. 2005;511:151-8.

196. Klamer D, Engel JA, Svensson L. Phencyclidine-induced behaviour in mice prevented by methylene blue. Basic Clin Pharmacol Toxicol. 2004;94:65-72.

197. Narsapur SL, Naylor GJ. Methylene blue. A possible treatment for manic depressive psychosis. J Affect Disord. 1983;5:155-61.

198. Mori T, Koyama N, Segawa T, Maeda M, Maruyama N, Kinoshita N, et al Methylene blue modulates beta-secretase, reverses cerebral amyloidosis, and improves cognition in transgenic mice. J Biol Chem. 2014;289: 30303-17.

199. Medina DX, Caccamo A, Oddo S. Methylene blue reduces abeta levels and rescues early cognitive deficit by increasing proteasome activity. Brain Pathol. 2011:21:140-9.

200. Rodriguez P, Zhou W, Barrett DW, Altmeyer W, Gutierrez JE, Li J, et al. Multimodal Randomized Functional MR Imaging of the Effects of Methylene Blue in the Human Brain. Radiology. 2016;281:516-26. 
201. Wischik CM, Staff RT, Wischik DJ, Bentham P, Murray AD, Storey JM, et al. Tau aggregation inhibitor therapy: an exploratory phase 2 study in mild or moderate Alzheimer's disease. J Alzheimer's Dis. 2015;44:705-20.

202. Gonzalez-Lima F, Auchter A. Protection against neurodegeneration with low-dose methylene blue and near-infrared light. Front Cell Neurosci. 2015;9:179.

203. Wainwright M, Crossley KB. Methylene Blue--a therapeutic dye for all seasons? J Chemother. 2002;14:431-43.

204. Peter C, Hongwan D, Kupfer A, Lauterburg BH. Pharmacokinetics and organ distribution of intravenous and oral methylene blue. Eur J Clin Pharmacol. 2000;56:247-50.

205. Wright RO, Lewander WJ, Woolf AD. Methemoglobinemia: etiology, pharmacology, and clinical management. Ann Emerg Med. 1999;34:646-56.

206. Hamblin MR. Mechanisms and applications of the anti-inflammatory effects of photobiomodulation. AIMS Biophysics. 2017;4:337-61.

207. Masoumipoor M, Jameie SB, Janzadeh A, Nasirinezhad F, Soleimani M, Kerdary M. Effects of 660- and 980-nm low-level laser therapy on neuropathic pain relief following chronic constriction injury in rat sciatic nerve. Lasers Med Sci. 2014;29:1593-8.

208. Xu Z, Guo X, Yang Y, Tucker D, Lu Y, Xin N, et al. Low-Level Laser Irradiation Improves Depression-Like Behaviors in Mice. Mol Neurobiol. 2017:54:4551-9.

209. Bibikova A, Belkin V, Oron U. Enhancement of angiogenesis in regenerating gastrocnemius muscle of the toad (Bufo viridis) by low-energy laser irradiation. Anat Embryol. 1994;190:597-602.

210. Bibikova A, Oron U. Promotion of muscle regeneration in the toad (Bufo viridis) gastrocnemius muscle by low-energy laser irradiation. Anat Rec. 1993;235:374-80

211. Brignardello-Petersen R. Laser use may improve pain and wound healing in patients with recurrent aphtous stomatitis. J Am Dent Assoc. 2017;148:e112.

212. Santos MOD, Latrive A, De Castro PAA, De Rossi W, Zorn TMT, Samad RE, et al. Multimodal evaluation of ultra-short laser pulses treatment for skin burn injuries. Biomed Opt Express. 2017;8:1575-88.

213. Yildirimturk S, Sirin Y, Soluk Tekkesin M, Gurler G, Firat D. The effects of lowlevel laser therapy on the healing of bone defects in streptozotocininduced diabetic rats: A histological and morphometric evaluation. J Cosmet Laser Ther. 2017;19:397-403.

214. Takenori A, Ikuhiro M, Shogo U, Hiroe K, Junji S, Yasutaka T, et al. Immediate pain relief effect of low level laser therapy for sports injuries: Randomized, double-blind placebo clinical trial. J Sci Med Sport. 2016;19:980-3.

215. Paolillo AR, Paolillo FR, Joao JP, Joao HA, Bagnato VS. Synergic effects of ultrasound and laser on the pain relief in women with hand osteoarthritis. Lasers Med Sci. 2015;30:279-86

216. Oron U, Yaakobi T, Oron A, Hayam G, Gepstein L, Rubin O, et al. Attenuation of infarct size in rats and dogs after myocardial infarction by low-energy laser irradiation. Lasers Surg Med. 2001;28:204-11.

217. Barolet D, Christiaens F, Hamblin MR. Infrared and skin: Friend or foe. J Photochem Photobiol B Biol. 2016;155:78-85.

218. Rojas JC, Bruchey AK, Gonzalez-Lima F. Low-level light therapy improves cortical metabolic capacity and memory retention. J Alzheimer's Dis. 2012; 32:741-52.

219. Yao J, Irwin RW, Zhao L, Nilsen J, Hamilton RT, Brinton RD. Mitochondria bioenergetic deficit precedes Alzheimer's pathology in female mouse model of Alzheimer's disease. Proc Natl Acad Sci U S A. 2009;106:14670-5.

220. Readnower RD, Sauerbeck AD, Sullivan PG. Mitochondria, Amyloid beta, and Alzheimer's Disease. Int J Alzheimer's Dis. 2011:104545.

221. Rhein V, Baysang G, Rao S, Meier F, Bonert A, Muller-Spahn F, et al. Amyloidbeta leads to impaired cellular respiration, energy production and mitochondrial electron chain complex activities in human neuroblastoma cells. Cell Mol Neurobiol. 2009;29:1063-71.

222. Yang SY, He XY, Miller D. HSD17B10: a gene involved in cognitive function through metabolism of isoleucine and neuroactive steroids. Mol Genet Metab. 2007;92:36-42.

223. Yao J, Taylor M, Davey F, Ren Y, Aiton J, Coote P, et al. Interaction of amyloid binding alcohol dehydrogenase/Abeta mediates up-regulation of peroxiredoxin in the brains of Alzheimer's disease patients and a transgenic Alzheimer's disease mouse model. Mol Cell Neurosci. 2007;35:377-82.

224. He XY, Wen GY, Merz G, Lin D, Yang YZ, Mehta $P$, et al. Abundant type 10 17 beta-hydroxysteroid dehydrogenase in the hippocampus of mouse Alzheimer's disease model. Brain Res Mol Brain Res. 2002;99:46-53.

225. Takuma K, Yao J, Huang J, Xu H, Chen X, Luddy J, et al. ABAD enhances Abeta-induced cell stress via mitochondrial dysfunction. Faseb J. 2005;19: 597-8.
226. Zakaria A, Hamdi N, Abdel-Kader RM. Methylene Blue Improves Brain Mitochondrial ABAD Functions and Decreases Abeta in a Neuroinflammatory Alzheimer's Disease Mouse Model. Mol Neurobiol. 2016; 53:1220-8.

227. Paban V, Manrique C, Filali M, Maunoir-Regimbal S, Fauvelle F, AlescioLautier B. Therapeutic and preventive effects of methylene blue on Alzheimer's disease pathology in a transgenic mouse model. Neuropharmacology. 2014;76 Pt A:68-79.

228. Gao YL, Wang N, Sun FR, Cao XP, Zhang W, Yu JT. Tau in neurodegenerative disease. Ann Transl Med. 2018;6:175.

229. Wischik CM, Edwards PC, Lai RY, Roth M, Harrington CR. Selective inhibition of Alzheimer disease-like tau aggregation by phenothiazines. Proc Natl Acad Sci U S A. 1996:93:11213-8.

230. Hattori M, Sugino E, Minoura K, In Y, Sumida M, Taniguchi T, et al. Different inhibitory response of cyanidin and methylene blue for filament formation of tau microtubule-binding domain. Biochem Biophys Res Commun. 2008; 374:158-63.

231. Atamna H, Kumar R. Protective role of methylene blue in Alzheimer's disease via mitochondria and cytochrome c oxidase. J Alzheimer's Dis. 2010; 20(Suppl 2):S439-52.

232. Atamna $\mathrm{H}$. Amino acids variations in amyloid-beta peptides, mitochondrial dysfunction, and new therapies for Alzheimer's disease. J Bioenerg Biomembr. 2009:41:457-64.

233. Callaway NL, Riha PD, Bruchey AK, Munshi Z, Gonzalez-Lima F. Methylene blue improves brain oxidative metabolism and memory retention in rats. Pharmacol Biochem Behav. 2004;77:175-81.

234. De Taboada L, Yu J, El-Amouri S, Gattoni-Celli S, Richieri S, McCarthy T, et al. Transcranial laser therapy attenuates amyloid-beta peptide neuropathology in amyloid-beta protein precursor transgenic mice. J Alzheimer's Dis. 2011; 23:521-35.

235. Purushothuman S, Johnstone DM, Nandasena C, Eersel J, Ittner LM, Mitrofanis J, et al. Near infrared light mitigates cerebellar pathology in transgenic mouse models of dementia. Neurosci Letters. 2015;591:155-9.

236. Oron A, Oron U. Low-Level Laser Therapy to the Bone Marrow Ameliorates Neurodegenerative Disease Progression in a Mouse Model of Alzheimer's Disease: A Minireview. Photomed Laser Surg. 2016;34:627-30.

237. Meng C, He Z, Xing D. Low-level laser therapy rescues dendrite atrophy via upregulating BDNF expression: implications for Alzheimer's disease. J Neurosci. 2013;33:13505-17.

238. Moreira PI, Carvalho C, Zhu X, Smith MA, Perry G. Mitochondrial dysfunction is a trigger of Alzheimer's disease pathophysiology. Biochimica Biophysica Acta. 2010;1802:2-10.

239. Rojas JC, Bruchey AK, Gonzalez-Lima F. Neurometabolic mechanisms for memory enhancement and neuroprotection of methylene blue. Prog Neurobiol. 2012;96:32-45.

240. Scheindlin S. Something old... something blue. Mol Intervent. 2008:8:268273.

241. Zhao M, Liang F, Xu H, Yan W, Zhang J. Methylene blue exerts a neuroprotective effect against traumatic brain injury by promoting autophagy and inhibiting microglial activation. Mol Med Rep. 2016;13:13-20

242. Lu J, Marmarou A, Choi S, Maas A, Murray G, Steyerberg EW. Mortality from traumatic brain injury. Acta Neurochirurgica Suppl. 2005;95:281-5.

243. Shen J, Xin W, Li Q, Gao Y, Yuan L, Zhang J. Methylene Blue Reduces Neuronal Apoptosis and Improves Blood-Brain Barrier Integrity After Traumatic Brain Injury. Front Neurol. 2019:10:1133.

244. Hamblin MR. Photobiomodulation for traumatic brain injury and stroke. J Neurosci Res. 2018;96:731-43.

245. Oron A, Oron U, Streeter J, de Taboada L, Alexandrovich A, Trembovler V, et al. Low-level laser therapy applied transcranially to mice following traumatic brain injury significantly reduces long-term neurological deficits. J Neurotrauma. 2007;24:651-6.

246. Wu Q, Xuan W, Ando T, Xu T, Huang L, Huang YY, et al. Low-level laser therapy for closed-head traumatic brain injury in mice: effect of different wavelengths. Lasers Surg Med. 2012:44:218-26.

247. Zhang Q, Zhou C, Hamblin MR, Wu MX. Low-level laser therapy effectively prevents secondary brain injury induced by immediate early responsive gene X-1 deficiency. J Cerebral Blood Flow Metab. 2014;34:1391-401.

248. Naeser MA, Saltmarche A, Krengel MH, Hamblin MR, Knight JA. Improved cognitive function after transcranial, light-emitting diode treatments in chronic, traumatic brain injury: two case reports. Photomed Laser Surg. 2011;29:351-8. 
249. Nawashiro H, Wada K, Nakai K, Sato S. Focal increase in cerebral blood flow after treatment with near-infrared light to the forehead in a patient in a persistent vegetative state. Photomed Laser Surg. 2012;30:231-3.

250. Walter-Sack I, Rengelshausen J, Oberwittler H, Burhenne J, Mueller O, Meissner $P$, et al. High absolute bioavailability of methylene blue given as an aqueous oral formulation. Eur J Clin Pharmacol. 2009;65:179-89.

251. Lin AL, Poteet E, Du F, Gourav RC, Liu R, Wen Y, et al. Methylene blue as a cerebral metabolic and hemodynamic enhancer. PloS One. 2012;7:e46585.

252. Wen Y, Li W, Poteet EC, Xie L, Tan C, Yan LJ, et al. Alternative mitochondrial electron transfer as a novel strategy for neuroprotection. J Biol Chem. 2011; 286:16504-15.

253. Di Y, He YL, Zhao T, Huang X, Wu KW, Liu SH, et al. Methylene Blue Reduces Acute Cerebral Ischemic Injury via the Induction of Mitophagy. Mol Med. 2015;21:420-9

254. Tucker LD, Lu Y, Dong Y, Yang L, Li Y, Zhao N, et al. Photobiomodulation Therapy Attenuates Hypoxic-Ischemic Injury in a Neonatal Rat Model. J Mol Neurosci. 2018:65:514-26.

255. Detaboada L, llic S, Leichliter-Martha S, Oron U, Oron A, Streeter J. Transcranial application of low-energy laser irradiation improves neurological deficits in rats following acute stroke. Lasers Surg Med. 2006; 38:70-3.

256. Oron A, Oron U, Streeter J, De Taboada L, Alexandrovich A, Trembovler V, et al. Near infrared transcranial laser therapy applied at various modes to mice following traumatic brain injury significantly reduces long-term neurological deficits. J Neurotrauma. 2012;29:401-7.

257. Lapchak PA, Wei J, Zivin JA. Transcranial infrared laser therapy improves clinical rating scores after embolic strokes in rabbits. Stroke. 2004;35:1985-8.

258. Brondon P, Stadler I, Lanzafame RJ. A study of the effects of phototherapy dose interval on photobiomodulation of cell cultures. Lasers Surg Med. 2005;36:409-13.

259. Wong-Riley MT, Liang HL, Eells JT, Chance B, Henry MM, Buchmann E, et al. Photobiomodulation directly benefits primary neurons functionally inactivated by toxins: role of cytochrome c oxidase. J Biol Chem. 2005;280: 4761-71.

260. Desmond DW, Moroney JT, Sano M, Stern Y. Incidence of dementia after ischemic stroke: results of a longitudinal study. Stroke. 2002;33:2254-60.

261. Censori B, Manara O, Agostinis C, Camerlingo M, Casto L, Galavotti B, et al. Dementia after first stroke. Stroke. 1996;27:1205-10.

262. Hamblin MR. Photobiomodulation for Alzheimer's Disease: Has the Light Dawned? Photonics. 2019;6.

263. Wang R, Dong Y, Lu Y, Zhang W, Brann DW, Zhang Q. Photobiomodulation for Global Cerebral Ischemia: Targeting Mitochondrial Dynamics and Functions. Mol Neurobiol. 2019:56:1852-69.

264. Naylor GJ, Martin B, Hopwood SE, Watson Y. A two-year double-blind crossover trial of the prophylactic effect of methylene blue in manicdepressive psychosis. Biol Psychiatry. 1986;21:915-20.

265. Naylor GJ, Smith AH, Connelly P. A controlled trial of methylene blue in severe depressive illness. Biol Psychiatry. 1987;22:657-9.

266. Alda M, McKinnon M, Blagdon R, Garnham J, MacLellan S, O'Donovan C, et al. Methylene blue treatment for residual symptoms of bipolar disorder: randomised crossover study. Br J Psychiatr. 2017;210:54-60.

267. Fenn AM, Gensel JC, Huang Y, Popovich PG, Lifshitz J, Godbout JP. Immune activation promotes depression 1 month after diffuse brain injury: a role for primed microglia. Biol Psychiatry. 2014;76:575-84.

268. Fann JR, Hart T, Schomer KG. Treatment for depression after traumatic brain injury: a systematic review. J Neurotrauma. 2009;26:2383-402.

269. Fenn AM, Skendelas JP, Moussa DN, Muccigrosso MM, Popovich PG, Lifshitz $J$, et al. Methylene blue attenuates traumatic brain injury-associated neuroinflammation and acute depressive-like behavior in mice. J Neurotrauma. 2015:32:127-38.

270. Joca SRL, Sartim AG, Roncalho AL, Diniz CFA, Wegener G. Nitric oxide signalling and antidepressant action revisited. Cell Tissue Res. 2019;377:45-58.

271. Naylor GJ, Smith AH, Connelly P. Methylene blue in mania. Biol Psychiatry. 1988:24:941-2

272. Gillman PK. Methylene blue is a potent monoamine oxidase inhibitor. Can J Anaesth. 2008:55:311-2 author reply 312.

273. Jakubovic A, Necina J. The effect of methylene blue on the monoamine oxidase activity of the liver and brain of rats after various routes of administration. Arzneimittel-Forschung. 1963;13:134-6.

274. Mohammed HS. Transcranial low-level infrared laser irradiation ameliorates depression induced by reserpine in rats. Lasers Med Sci. 2016;31:1651-6.
275. Quah-Smith I, Smith C, Crawford JD, Russell J. Laser acupuncture for depression: a randomised double blind controlled trial using low intensity laser intervention. J Affect Disord. 2013;148:179-87.

276. Quah-Smith JI, Tang WM, Russell J. Laser acupuncture for mild to moderate depression in a primary care setting--a randomised controlled trial. Acupuncture Med. 2005;23:103-11.

277. Caldieraro MA, Sani G, Bui E, Cassano P. Long-Term Near-Infrared Photobiomodulation for Anxious Depression Complicated by Takotsubo Cardiomyopathy. J Clin Psychopharmacol. 2018;38:268-70.

278. Kim GH, Kim JE, Rhie SJ, Yoon S. The Role of Oxidative Stress in Neurodegenerative Diseases. Exp Neurobiol. 2015;24:325-40.

279. Shukla V, Mishra SK, Pant HC. Oxidative stress in neurodegeneration. Adv Pharmacol Sci. 2011:572634

280. Kupsch A, Schmidt W, Gizatullina Z, Debska-Vielhaber G, Voges J, Striggow $F$, et al. 6-Hydroxydopamine impairs mitochondrial function in the rat model of Parkinson's disease: respirometric, histological, and behavioral analyses. J Neural Transm (Vienna). 2014;121:1245-57.

281. Glinka Y, Tipton KF, Youdim MB. Nature of inhibition of mitochondrial respiratory complex I by 6-Hydroxydopamine. J Neurochem. 1996;66:2004-10.

282. Glinka YY, Youdim MB. Inhibition of mitochondrial complexes I and IV by 6hydroxydopamine. Eur J Pharmacol. 1995;292:329-32.

283. Perumal AS, Tordzro WK, Katz M, Jackson-Lewis V, Cooper TB, Fahn S, et al. Regional effects of 6-hydroxydopamine (6-OHDA) on free radical scavengers in rat brain. Brain Res. 1989;504:139-41.

284. Smith ES, Clark ME, Hardy GA, Kraan DJ, Biondo E, Gonzalez-Lima F, et al. Daily consumption of methylene blue reduces attentional deficits and dopamine reduction in a 6-OHDA model of Parkinson's disease. Neuroscience. 2017;359:8-16.

285. Rojas JC, Simola N, Kermath BA, Kane JR, Schallert T, Gonzalez-Lima F. Striatal neuroprotection with methylene blue. Neuroscience. 2009;163:877-89.

286. Bhurtel S, Katila N, Neupane S, Srivastav S, Park PH, Choi DY. Methylene blue protects dopaminergic neurons against MPTP-induced neurotoxicity by upregulating brain-derived neurotrophic factor. Ann N Y Acad Sci. 2018; 1431:58-71.

287. Reinhart F, Massri NE, Torres N, Chabrol C, Molet J, Johnstone DM, et al. The behavioural and neuroprotective outcomes when $670 \mathrm{~nm}$ and $810 \mathrm{~nm}$ near infrared light are applied together in MPTP-treated mice. Neurosci Res. 2017:117:42-7.

288. Reinhart F, El Massri N, Johnstone DM, Stone J, Mitrofanis J, Benabid AL, et al. Near-infrared light $(670 \mathrm{~nm})$ reduces MPTP-induced parkinsonism within a broad therapeutic time window. Exp Brain Res. 2016;234:1787-94.

289. Johnstone DM, el Massri N, Moro C, Spana S, Wang XS, Torres N, et al. Indirect application of near infrared light induces neuroprotection in a mouse model of parkinsonism - an abscopal neuroprotective effect. Neuroscience. 2014;274:93-101.

290. O'Brien JA, Austin PJ. Effect of Photobiomodulation in Rescuing Lipopolysaccharide-Induced Dopaminergic Cell Loss in the Male SpraqueDawley Rat. Biomolecules. 2019;9.

291. Santos L, Olmo-Aguado SD, Valenzuela PL, Winge K, Iglesias-Soler $E_{\text {, }}$ Arguelles-Luis J, et al. Photobiomodulation in Parkinson's disease: A randomized controlled trial. Brain Stimul. 2019;12:810-2.

292. Hamilton C, Hamilton D, Nicklason F, El Massri N, Mitrofanis J. Exploring the use of transcranial photobiomodulation in Parkinson's disease patients. Neural Regen Res. 2018;13:1738-40.

293. Hennessy M, Hamblin MR. Photobiomodulation and the brain: a new paradigm. J Opt. 2017;19:013003.

294. Silveira PCL, Ferreira GK, Zaccaron RP, Glaser V, Remor AP, Mendes C, et al. Effects of photobiomodulation on mitochondria of brain, muscle, and C6 astroglioma cells. Med Eng Physics. 2019;71:108-13.

295. Hamblin MR. Mechanisms and Mitochondrial Redox Signaling in Photobiomodulation. Photochem Photobiol. 2018:94:199-212.

296. Duicu OM, Privistirescu A, Wolf A, Petrus A, Danila MD, Ratiu CD, et al. Methylene blue improves mitochondrial respiration and decreases oxidative stress in a substrate-dependent manner in diabetic rat hearts. Can J Physiol Pharmacol. 2017;95:1376-82

297. Atamna H, Nguyen A, Schultz C, Boyle K, Newberry J, Kato H, et al. Methylene blue delays cellular senescence and enhances key mitochondrial biochemical pathways. Faseb J. 2008;22:703-12.

298. McCord JM, Fridovich I. The utility of superoxide dismutase in studying free radical reactions. II. The mechanism of the mediation of cytochrome $c$ reduction by a variety of electron carriers. J Biol Chem. 1970;245:1374-7. 
299. Murphy MP. How mitochondria produce reactive oxygen species. Biochem J. 2009:417:1-13.

300. Kussmaul L, Hirst J. The mechanism of superoxide production by NADH: ubiquinone oxidoreductase (complex I) from bovine heart mitochondria. Proc Natl Acad Sci U S A. 2006;103:7607-12.

301. Minutoli L, Puzzolo D, Rinaldi M, Irrera N, Marini H, Arcoraci V, et al. ROSMediated NLRP3 Inflammasome Activation in Brain, Heart, Kidney, and Testis Ischemia/Reperfusion Injury. Oxid Med Cell Longev. 2016;2016:2183026.

302. Jo EK, Kim JK, Shin DM, Sasakawa C. Molecular mechanisms regulating NLRP3 inflammasome activation. Cell Mol Immunol. 2016;13:148-59.

303. Heid ME, Keyel PA, Kamga C, Shiva S, Watkins SC, Salter RD. Mitochondrial reactive oxygen species induces NLRP3-dependent lysosomal damage and inflammasome activation. J Immunol. 2013;191:5230-8.

304. Zhou L, Flores J, Noel A, Beauchet O, Sjostrom PJ, LeBlanc AC. Methylene blue inhibits Caspase-6 activity, and reverses Caspase-6-induced cognitive impairment and neuroinflammation in aged mice. Acta Neuropathol Commun. 2019;7:210.

305. Berrocal M, Caballero-Bermejo M, Gutierrez-Merino C, Mata AM. Methylene Blue Blocks and Reverses the Inhibitory Effect of Tau on PMCA Function. Int J Mol Sci. 2019;20.

306. Gureev AP, Shaforostova EA, Popov VN, Starkov AA. Methylene blue does not bypass Complex III antimycin block in mouse brain mitochondria. Febs Lett. 2019;593:499-503.

307. Chen ZW, Liu A, Liu Q, Chen J, Li WM, Chao XJ, et al. MEF2D Mediates the Neuroprotective Effect of Methylene Blue Against Glutamate-Induced Oxidative Damage in HT22 Hippocampal Cells. Mol Neurobiol. 2017;54: 2209-22.

308. Passarella S, Karu T. Absorption of monochromatic and narrow band radiation in the visible and near IR by both mitochondrial and nonmitochondrial photoacceptors results in photobiomodulation. J Photochem Photobiol B Biol. 2014;140:344-58

309. Holm L, Saraste M, Wikstrom M. Structural models of the redox centres in cytochrome oxidase. EMBO J. 1987;6:2819-23.

310. Sarti P, Forte E, Mastronicola D, Giuffre A, Arese M. Cytochrome c oxidase and nitric oxide in action: molecular mechanisms and pathophysiological implications. Biochimica Biophys Acta., 1817. 2012:610-9.

311. Lane N. Cell biology: power games. Nature. 2006;443:901-3.

312. Chen AC, Arany PR, Huang YY, Tomkinson EM, Sharma SK, Kharkwal GB, et al. Low-level laser therapy activates NF-kB via generation of reactive oxygen species in mouse embryonic fibroblasts. PloS One. 2011;6:e22453.

313. Hwang MH, Shin JH, Kim KS, Yoo CM, Jo GE, Kim JH, et al. Low level light therapy modulates inflammatory mediators secreted by human annulus fibrosus cells during intervertebral disc degeneration in vitro. Photochem photobiol. 2015:91:403-10.

314. Yamaura M, Yao M, Yaroslavsky I, Cohen R, Smotrich M, Kochevar IE. Low level light effects on inflammatory cytokine production by rheumatoid arthritis synoviocytes. Lasers Surg Med. 2009;41:282-90.

315. Sakurai Y, Yamaguchi M, Abiko Y. Inhibitory effect of low-level laser irradiation on LPS-stimulated prostaglandin E2 production and cyclooxygenase-2 in human gingival fibroblasts. Eur J Oral Sci. 2000;108:29-34.

316. Lautrup S, Sinclair DA, Mattson MP, Fang EF. NAD(+) in Brain Aging and Neurodegenerative Disorders. Cell Metab. 2019;30:630-55.

317. Mattson MP, Arumugam TV. Hallmarks of Brain Aging: Adaptive and Pathological Modification by Metabolic States. Cell Metab. 2018;27:1176-99.

Ready to submit your research? Choose BMC and benefit from:

- fast, convenient online submission

- thorough peer review by experienced researchers in your field

- rapid publication on acceptance

- support for research data, including large and complex data types

- gold Open Access which fosters wider collaboration and increased citations

- maximum visibility for your research: over $100 \mathrm{M}$ website views per year

At $\mathrm{BMC}$, research is always in progress.

Learn more biomedcentral.com/submissions 